\title{
Mesenchymal Stem Cell-Derived Extracellular Vesicles Carrying miRNA as a Potential Multi Target Therapy to COVID-19: an In Silico Analysis
}

\author{
lago Carvalho Schultz ${ }^{1}$ • Ana Paula Santin Bertoni ${ }^{1}$ • Márcia Rosângela Wink ${ }^{1}$ \\ Accepted: 12 January 2021 / Published online: 28 January 2021 \\ (C) The Author(s), under exclusive licence to Springer Science+Business Media, LLC part of Springer Nature 2021
}

\begin{abstract}
In the end of 2019 COVID-19 emerged as a new threat worldwide and this disease present impaired immune system, exacerbated production of inflammatory cytokines, and coagulation disturbs. Mesenchymal stem cell (MSC) derived extracellular vesicles (EVs) have emerged as a therapeutic option due to its intrinsic properties to alleviate inflammatory responses, capable to promote the restoring of injured tissue. EVs contain heterogeneous cargo, including active microRNAs, small noncoding sequences involved in post-transcriptional gene repression or degradation and can attach in multiple targets. This study investigated whether the MSC-EVs miRNA cargo has the capacity to modulate the exacerbated cytokines, cell death and coagulation disturbs present in severe COVID-19. Through bioinformatics analysis, four datasets of miRNA, using different stem cell tissue sources (bone marrow, umbilical cord and adipose tissue), and one dataset of mRNA (bone marrow) were analyzed. 58 miRNAs overlap in the four miRNA datasets analyzed. Sequentially, those miRNAs present in at least two datasets, were analyzed using miRWalk for the 3'UTR binding target mRNA. The result predicted 258 miRNAs for exacerbated cytokines and chemokines, 266 miRNAs for cell death genes and 148 miRNAs for coagulation cascades. Some miRNAs may simultaneously attenuate inflammatory agents, inhibit cell death genes and key factors of coagulation cascade, consequently preventing tissue damage and coagulation disturbs. Therefore, the MSC-derived EVs due to their heterogeneous cargo are a potential multitarget approach able to improve the survival rates of severe COVID-19 patients.
\end{abstract}

Keywords Sars-Cov-2 - ARDS - miRNA - Mesenchymal stem cell · MSC · Microvesicles · Exosomes · COVID-19 · Bioinformatics

\section{Introduction}

In December 2019 a new $\beta$-virus from the family Coronaviridae was first isolated from pneumonia cases in Wuhan city, China, and started a pandemic affecting the population worldwide [1]. Due to the genomic similarity of $79 \%$

Ana Paula Santin Bertoni and Márcia Rosângela Wink shares senior authorship

This article belongs to the Topical Collection: Special Issue on COVID19 Pandemic and Stem Cells

Guest Editor: Mariusz Z. Ratajczak

Márcia Rosângela Wink

mwink@ufcspa.edu.br; marciawink@yahoo.com.br

1 Laboratório de Biologia Celular, Departamento de Ciências Básicas da Saúde, Universidade Federal de Ciências da Saúde de Porto Alegre (UFCSPA), Rua Sarmento Leite, 245, Porto Alegre, RS 90050-170, Brazil to Sars-CoV [2], also a $\beta$-virus, this pathogen was first called of 2019 novel coronavirus (2019-nCoV) and then officially called as Sars-CoV-2, while the WHO named the disease caused by the virus, Coronavirus disease-19 (COVID-19) [3]. To date, January 2021, over 88 million cases have been reported across the globe, resulting more than 1.9 million deaths (covid19.who.int). The genome of Sars-CoV-2, similarly to other coronaviruses, is a single-stranded ribonucleic acid (RNA) with positive polarity [4] and the viral membrane contains 4 structures: membrane protein (M), Spike protein $(\mathrm{S})$, Nucleocapsid protein $(\mathrm{N})$ and Envelope protein (E). Similar to Sars-CoV infection, the spike of Sars-CoV-2 dictates the host tropism and pathogenicity [5]. The main mechanism of transmission is human to human contact or contact with virus aerosolization. Once inside the human body, the receptor binding domain (RBD) of Sars-CoV-2 spike glycoprotein attaches to the Angiotensin Converting Enzyme 2 (ACE2) receptor and is cleavage by Transmembrane Serin Protease 2 (TMPRSS2) helping the 
viral internalization mainly of type II alveolar cells. The respiratory tract have a widely expression of the ACE2 receptors and the airways are the main entrance of the virus [6]. Other tissues such as cardiac, kidney, bowel, brain, endothelial cells and others also express the ACE2 receptor [7]. Other proteases expressed in various tissues may also cleave the Sars-CoV-2 spike protein [8] and one of them, as showed in previous studies with Sars-CoV, is the coagulation Factor Xa, colocalized with TMPRSS2 in the cell membrane [9, 10]. Patients with preexisting conditions are more vulnerable of getting infected and develop a poor prognosis of COVID-19 [11]. Preexisting conditions such as pulmonary and cardiac diseases emerge as the highest risk groups for severe COVID-19 [12] and these patients may have a higher baseline expression of the receptor ACE2 and Factor X in these cell populations, what could put them at increased risk of host cell infection by Sars-CoV-2, with Factor X serving as one of the cleavage proteases for spike protein [9].

A major part of COVID-19 cases are asymptomatic, although around $20 \%$ of patients are severely or critically unwell $[13,14]$. In those individuals, who present symptoms, common clinical manifestations of COVID-19 include fever, cough, fatigue, sputum production, shortness of breath, sore throat, headache, loss of taste and smell, pneumonia and more advanced cases progress to Acute Respiratory Distress Syndrome (ARDS), coagulation disturbs [15], multiple organ failure, septic shock and death [16]. The patients who progressed to ARDS are evaluate following the Berlin definition [17]. Overall, around $36 \%$ of the patients died within 28 days of intensive care unit (ICU) admission [18].

ICU patients admitted with pneumonia who progress to ARDS have systemic inflammation, and present altered plasma levels of lymphocytopenia, D-dimer, C-reactive protein, LDH and inflammatory cytokines such as IL-6, IL-1 $\beta$, IL-2, IL-7, IL-8, IL-9, IL-10, IL-17, G-CSF, MCP-1 (CCL2), MIP$1 \alpha$ (CCL3), MCP-3 (CCL7) and CXCL10 (IP-10), IL-18, IL33, IL1- $\alpha$, IL-15. D-dimer, a product of fibrin degradation, is consider a biomarker of poor prognosis in COVID-19 when the measurements are $>1 \mu \mathrm{g} / \mathrm{mL}[19,20]$. Altered prothrombin time was also positively correlated with patient mortality [21]. Tissue factor, usually, is not express by endothelial cells and leukocytes, but the expression can be induced by inflammatory stimuli such as cytokines TNF- $\alpha$ and IL- $1 \beta$. High levels of pro-inflammatory agents, specially IL- 6 , IL- $1 \beta$ and TNF- $\alpha$ were associated to the harshness and progression of the disease [13, 19, 22-24]. Although, despite the elevated baseline levels of the proinflammatory agents in COVID-19, they are significantly lower than non-COVID-19 related ARDS patients [25]. Recently, in vitro and in vivo evidencebased, Karki and colleagues, 2020 showed that TNF- $\alpha$ and INF- $\gamma$ together can induce cell death through PANoptosis (pyroptosis, apoptosis and necrosis) [26]. In addition, they evidenced that the other cytokines, despite exacerbated, are not related to cell death in the acute inflammation of COVID-19.

In the end of 2020, vaccines for COVID-19 have been approved in a few countries. So far, two vaccines were approved in the USA and three in the UK by their respective regulatory agencies, but no specific treatment has yet been officially approved to treat COVID-19. However, prophylactic doses of low molecular weight heparin are recommended by the International Society on Thrombosis and Hemostasis for all hospitalized COVID-19 patients, except for those with active bleeding or low platelet counts, aiming the reduction of coagulation disturbs as the venous thromboembolic event (VTE) [27]. Heparin is an inhibitor mainly of the Factor Xa and IIa, components of the coagulation cascade [28]. Treatment of hospitalized COVID-19 patients with heparin improved the outcomes and survival rates compared to those patients who did not receive the anticoagulant treatment [21]. However, a few patients shows heparin resistance and have extremely high levels of Factor VIII, fibrinogen and D-dimer [29]. Yet, doses and time of administration of anticoagulant treatment or prophylaxis still diverge between hospitals and medical institutions $[18,30]$.

A considerable number of studies are being carried out to test different therapeutic approaches [31]. One of these approaches is mesenchymal stem cells (MSCs), a therapy reported as a potent agent to attenuate inflammation, due to intrinsic characteristics of immunomodulation, and leading to lung tissue regeneration, useful features in severe COVID-19 cases clinical management. Still, after decades of the discovery of these cells, the definition of the nomenclature used to identify MSCs remains controversial and different terms have been used to name these cells. While a definition of the use of "stem" or "stromal" is not decided by International Society for Cellular Therapy, in the present study was used the term "Mesenchymal stem cells" to simplify the bibliographic search [32].

Until the submission of this paper a total of 46 clinical trials using mesenchymal stem cells to treat ARDS derived of COVID-19, 39 of these clinical trials are currently ongoing and six are completed (clinicaltrials.gov). A few clinical interventions using intravenous MSCs treatment in COVID19 showed improvement in clinical outcomes of treated patients with no adverse reactions [33-35]. Another therapeutic intervention is using the MSC-derived exosomes in cases of COVID-19. On clinicaltrals.gov there are three studies using this approach registered, NCT04276987 (a pilot study completed) using aerosol inhalation of the exosomes derived from allogenic adipose mesenchymal stem cells; NCT04491240 (completed and has positive results about safety and efficiency of clinical use) based on the NCT04276987 and the literature; and NCT04602442 (enrolling by invitation) also based on the NCT04276987, using aerosol inhalation of the exosomes derived from 
allogenic MSCs. Moreover, there is one report of clinical use of commercial MSC-derived exosomes intravenously $\left(\right.$ ExoFlo $\left.^{\mathrm{TM}}\right)$, obtained from allogenic bone marrow mesenchymal stem cells in COVID-19 patients [36].

In 2018, the International Society for Extracellular Vesicles (ISEV) updated their guidelines with basic information to help researchers in the communication process of their results with the extracellular vesicles (EVs). ISEV also encouraged the authors to submit their results in other database as EVTRACK $[37,38]$.

All types of cells shed EVs to cell-to-cell communication $[39,40]$. EVs can be subdivided in exosomes, microvesicles and apoptotic bodies. Exosomes, 40-120 nm, resulted from intraluminal budding of multivesicular bodies and fusion of these multivesicular bodies with cell membrane via the endosomal pathway. Microvesicles, 50-1.000 nm, are structures released from the outward budding and fission of the plasma membrane. Apoptotic bodies, 50-2000 nm, are vesicles released from the cell surface through outward budding of apoptotic cell membrane [41]. The MSCs-derived EVs can carry inside their lipidic bilayer, proteins, messenger RNAs (mRNAs), small and long non-coding RNAs (ncRNAs), DNA, lipids, and carbohydrates from parental cells which could shape the behavior of target cells contributing to the angiogenic, immunomodulatory and regenerative effect [42-44]. Thereby, the MSC-derived EVs present themselves as potentially cell-free agents on account of their similar characteristics with the parental cells. The benefits of EVs are the minimal risk of getting trapped in the lungs, production as "off-the-shelf" products in large quantities, minimal risk of tumor formation, non-immunogenic profile, ability to cross natural barriers and deliver bioactive compounds and others [44]. Studies using EVs in ARDS are incipient, but there are studies showing MSC-derived EVs present similar effects when compared to administration of MSCs [45, 46]. Gardin and collaborators, in a recent review, presented the treatment scenario and potential of exosomes in patients with heart and lung injuries [47]. MicroRNAs (miRNAs) are endogenous small ncRNAs that can be found within MSC-derived EVs and are associated with post-transcriptional gene repression or degradation [48]. Growing evidence shows that miRNAs could alleviate antiviral responses [49] since a single miRNA could target multiple genes. Functionally, miRNAs guides proteins of the Argonaute family to form a silencing complex through base pairing between the 5' portion of miRNA "seed sequence" (miRNA nucleotides 2-7/8) and complementary sites within the coding sequence (CDs), $3^{\prime}$ or $5^{\prime}$ untranslated regions (UTRs) of target RNAs [50].

The main objective of this study was to analyze the rationale behind the use of this biologic, cell-free structure, the MSC-derived extracellular vesicles, carrying heterogeneous inner cargo. In addition, using a bioinformatics approach, we analyzed evidence of vesicles carrying miRNAs content as modulators of acute inflammation, the PANoptosis cell death signature and the coagulation disturbs found in severe COVID-19 patients which resulted in an in silico prediction.

\section{Material and Methods}

A search of mRNA and miRNAs expression profiles in the MSC-derived EVs (microvesicles and exosomes) was performed using Gene Expression Omnibus (GEO) database (https://www.ncbi.nlm.nih.gov/geo/) restricting the search to Homo sapiens. The target prediction miRWalk 3.0 server (http://mirwalk.umm.uni-heidelberg.de/) was used to identify potential miRNAs binding sites within the mRNA sequences and to verify which miRNAs are experimentally validated based on its corresponding miRTarBase ID. The score $\geq 0$. 95 and more than 10 pairs were considered as the critical criteria for the predictive analysis. Considering the different platforms and methods between used datasets, the expression of miRNAs data was filtered based as follows: I) GSE69090 and GSE81151: miRNAs with zero counts were removed; II) GSE78865: miRNAs with same negative control values were removed; III) GSE71241: miRNAs that did not appear in at least one replicate sample were removed. A qualitative global score was generated to compare the levels of miRNA expression on each dataset (Sup.Table S1). The $5^{\prime}$ and $3^{\prime}$ mature miRNAs (miR-5p and miR-3p) were considered separately, except in the GSE78865 dataset that only miRNA precursor was available for analysis.

\section{Results}

To investigate the therapeutic potential of the MSC-derived EVs against COVID-19 lung and systemic inflammation, we conducted an in silico analysis of microRNA and mRNA profiles of human MSC-derived EVs in GEO database using GSE12243, GSE71241, GSE78865, GSE81151 and GSE69909 datasets. The main features of the used datasets are shown in Sup.Table 2.

The MSC-derived EVs cargo can vary depending on the biological source where they are extracted. Sup.Table 2 shows an overview of the dataset's characteristics used in this study. One dataset isolated MSCs from human umbilical cord [51, 52], three datasets used MSCs from human bone marrow [53-57] and one dataset used MSCs from human adipose tissue [58]. Also, there were differences regarding the technique of EVs isolation: two datasets used a commercial isolation kit (ExoQuick-TC kit) and the other three used serial and ultracentrifugation processes. As final product, one dataset tested only microvesicles, one dataset tested microvesicles and exosomes and three datasets used exclusively exosomes in their analysis. 
The integrative analysis revealed that 58 miRNAs were commonly expressed in all four collected miRNA datasets, however with different expression levels (Table 1). Among these 58 miRNAs, using the miRWalk server, we searched for the experimentally validated ones, which resulted in 27 miRNAs. They are highlighted in the Sup. Table 4, Figs. 1 and 2 with their respective miRTarBase IDs. Also, we considered as potential targets 361 miRNAs that were commonly shared in at least two datasets (Sup.Table 3). The miRNAs that were expressed only in one dataset or were absent in all datasets were not considered as potential targets. Next, we used miRWalk server to predict miRNAs binding sites, from those present in at least two datasets, in the 3'UTR region of CCL2, CCL3, CCL7, CSF3, CXCL10, CXCL8 (IL8), IL1B, IL1A, IL2, IL6, IL6R, IL7, IL9, IL10, IL15, IL17A, IL33, IL18 genes. As result, a total of 258 miRNAs were predicted to target the 3'UTR region of the mRNAs and are listed in (Sup.Table 4). The miRNAs that may interact concomitant with more than one mRNA target also shown in (Sup.Table 4).

In a separate analysis, aiming to investigate the interaction of the MSC-derived EVs miRNA cargo and the PANoptosis cell death pathway, suggested by [26], we executed the same previous protocol, only changing the target genes to TNF, IFNG, STAT1, IRF1, NOS2, RIPK1, RIPK3, FADD, GSDME, CASP3, CASP7, CASP8, MLKL, JAK1, JAK2. A total of 266 miRNAs were predicted to target the 3'UTR region of the mRNAs and are listed in Fig. 1. The miRNAs that may interact concomitant with more than one mRNA target also shown in Fig. 1.

Since coagulation disturbs has a direct relation with patients' mortality, a third analysis was performed to evaluate the interaction of the MSC-derived EVs miRNA cargo and genes involved in the coagulation cascade. Therefore, applying the same previous analysis, for the genes F2, F3, F5, F7, F8, F9, F10, F11, F12 and F13 a total of 148 miRNAs were predicted to target the 3 'UTR region of the mRNAs which are listed in Fig. 2. The miRNAs that may interact concomitant with more than one mRNA target also shown in Fig. 2.

We also investigated the profile of cytokines and chemokines, cell death and coagulation genes through the mRNA content from MSC-derived microvesicles in the GSE12243 dataset. In this dataset, three different quantities $(0.25 \mu \mathrm{g}, 0.5 \mu \mathrm{g}$ and $1 \mu \mathrm{g})$ of total RNA from vesicles were submitted to microarray analysis [57]. As shown in Supplementary Table 5, the microvesicles did not contain significant $(p \leq 0.05)$ or positive Pearson's correlation coefficient $\geq 0.8$ for our targets, suggesting that no functional protein will be produced.

\section{Discussion}

The pathogenesis of COVID-19, as shown in Fig. 3, is based on a dysregulation of innate and adaptative immune systems response after the infection mainly of the alveolar cells and endothelial cells by Sars-CoV-2, through specific receptor ACE2. Thus, the direct viral infection and the immune system dysregulation causes an acute inflammation and will result in alveolar and endothelial tissue damage. Furthermore, subsequently to acute inflammation and infected cell death the coagulation cascade will be triggered causing thrombotic events. Taken together, the blood clot formations and the upregulation of proinflammatory agents, the severe COVID-19 patients will develop the acute respiratory distress syndrome (ARDS), leading to organ failure and a fraction of them eventually will die [26, 59-62].

The magnitude of the "cytokine storm" has a direct relation with the harshness of COVID-19. Since the beginning of the pandemic, several studies have been published about COVID19 due to its importance and consequences globally. Like every new disease, in the beginning the biologic mechanisms, concepts and exact consequences are not well elucidated. Multiple papers refers to the exacerbated cytokines and chemokines levels as cytokine storm [42, 60, 63-69]. However, some reports affirm that this term cytokine storm might has been misused $[25,70,71]$. Despite the elevated levels of the cytokines and chemokines in COVID-19 derived ARDS, these levels are lower than those present in nonCOVID related ARDS or sepsis [25]. Yet, the authors found that despite the lower levels of cytokines compared to other diseases, D-dimer amounts in COVID-19 related ARDS are higher than non-COVID-19 related ARDS [25].

The coagulation and the immune system are directly linked [72]. COVID-19 may predispose to venous thromboembolic events due to inflammation, hypoxia and tissue damage. The most typical findings of severe COVID-19 patients are an increased concentration of D-dimer, a slight decrease in platelet counts and a prolongation of prothrombin time. Direct viral infection as well as inflammation-induced endothelial cell injury could result in a massive release of plasminogen activators, which could explain the higher concentration of D-dimer and fibrin degradation products found in the patients peripheral blood circulation [73, 74]. A cohort study shows that venous thromboembolism (VTE) in COVID-19 ICU patients are high and the rates of affected patients ranges between 35 and $45 \%$ [75]. Also, postmortem lung analysis, from patients who had died from COVID-19, revealed the presence of microthrombus in lung vascularity [76].

Interleukin-1 (IL-1), interleukin-6 (IL-6) and tumor necrosis factor (TNF) have all been shown to trigger acute endothelial cell activation. First, it was thought that TNF had a central role in coagulation activation in cases of sepsis. However, after studies using TNF blockers no significant decrease in coagulation was observed [77]. Then, studies proved that blocking IL-6 attenuates the coagulation activation [78]. Therefore, modulation of some cytokines could ameliorate the outcome of patients with coagulation disturbs $[79,80]$. 
Table 158 miRNAs of MSC-derived extracellular vesicles were commonly shared in all four analyzed datasets GSE71241, GSE78865, GSE81151 and GSE69909 regardless of the expression amount

\begin{tabular}{|c|c|c|c|c|c|c|}
\hline \multirow{2}{*}{$\begin{array}{l}\text { Mature miRNA } \\
\text { hsa-let-7a-5p }\end{array}$} & \multirow{2}{*}{$\begin{array}{l}\text { Precursor } \\
\text { hsa-let-7a-1/7a-2/7a-3 }\end{array}$} & \multirow{2}{*}{$\begin{array}{l}\text { GSE81151 } \\
* * *\end{array}$} & \multirow{2}{*}{$\begin{array}{l}\text { GSE69909 } \\
* * * * *\end{array}$} & \multirow{2}{*}{$\begin{array}{l}\text { GSE71241 } \\
* * *\end{array}$} & \multicolumn{2}{|l|}{ GSE78865 } \\
\hline & & & & & hsa-let-7a & $* * * *$ \\
\hline hsa-let-7e-5p & hsa-let-7e & $* *$ & $* * * *$ & $* * *$ & hsa-let-7e & $* *$ \\
\hline hsa-let-7f-5p & hsa-let-7f-1/7f-2 & $* * *$ & $* * * * *$ & $* * *$ & hsa-let-7f & $* * * *$ \\
\hline hsa-let-7 g-5p & hsa-let-7 g & $* *$ & $* * * *$ & $* * *$ & hsa-let-7 g & $* * *$ \\
\hline hsa-miR-10a-5p & hsa-mir-10a & $* *$ & $* * * *$ & $*$ & hsa-miR-10a & $* * * *$ \\
\hline hsa-miR-16-5p & hsa-mir-16-1/16-2 & $* * *$ & $* * * * * *$ & $* * *$ & hsa-miR-16 & $* * *$ \\
\hline hsa-miR-17-3p & hsa-mir-17 & $* *$ & $* * *$ & $* * *$ & hsa-miR-17 & $* *$ \\
\hline hsa-miR-23a-3p & hsa-mir-23a & $* *$ & $* * * * *$ & $* * *$ & hsa-miR-23a & $* * * *$ \\
\hline hsa-miR-19b-3p & hsa-mir-19b-1/19b-2 & $* *$ & $* * * *$ & $*$ & hsa-miR-19b & $* *$ \\
\hline hsa-miR-25-3p & hsa-mir-25 & $* *$ & $* * * *$ & $* * *$ & hsa-miR-25 & $* * * *$ \\
\hline hsa-miR-26a-5p & hsa-mir-26a-1/26a-2 & $* * * *$ & $* * * * *$ & $* * *$ & hsa-miR-26a & $* * * *$ \\
\hline hsa-miR-27b-3p & hsa-mir-27b & $* * *$ & $* * * *$ & $* * *$ & hsa-miR-27b & $* * * *$ \\
\hline hsa-miR-28-3p & hsa-mir-28 & $* * *$ & $* * *$ & $* * *$ & hsa-miR-28-3p & $* * * *$ \\
\hline hsa-miR-29a-3p & hsa-mir-29a & $* *$ & $* * * * *$ & $* * *$ & hsa-miR-29a & $* * * *$ \\
\hline hsa-miR-30c-5p & hsa-mir-30c-1/30c-2 & $* *$ & $* * * *$ & $*$ & hsa-miR-30c & $* *$ \\
\hline hsa-miR-29c-3p & hsa-mir-29c & $* *$ & $* * *$ & $* *$ & hsa-miR-29c & $* *$ \\
\hline hsa-miR-31-5p & hsa-mir-31 & $* *$ & $* * * * * *$ & $*$ & hsa-miR-31 & $* *$ \\
\hline hsa-miR-99a-5p & hsa-mir-99a & $* *$ & $* * * *$ & $* *$ & hsa-miR-99a & $* *$ \\
\hline hsa-miR-99b-5p & hsa-mir-99b & $* * *$ & $* * *$ & $*$ & hsa-miR-99b & $* * * *$ \\
\hline hsa-miR-100-5p & hsa-mir-100 & $* * *$ & $* * * * *$ & $* * *$ & hsa-miR-100 & $* * *$ \\
\hline hsa-miR-103a-3p & hsa-mir-103a-1/103a-2 & $* * *$ & $* * * *$ & $* *$ & hsa-miR-103 & $* * * *$ \\
\hline hsa-miR-124-3p & hsa-mir-124-1 & $* * *$ & $* *$ & $* * * *$ & hsa-miR-124 & $* * * *$ \\
\hline hsa-miR-125a-5p & hsa-mir-125a & $* * *$ & $* * * *$ & $*$ & hsa-miR-125a-5p & $* * * *$ \\
\hline hsa-miR-125b-1-3p & hsa-mir-125b-1 & $* *$ & $* * * *$ & $*$ & hsa-miR-125b & $* *$ \\
\hline hsa-miR-126-3p & hsa-mir-126 & $* *$ & $* * * *$ & $* * *$ & hsa-miR-126 & $* * * *$ \\
\hline hsa-miR-127-3p & hsa-mir-127 & $* * * *$ & $* * * *$ & $* *$ & hsa-miR-127-3p & $* * * *$ \\
\hline hsa-miR-130a-3p & hsa-mir-130a & $* *$ & $* * * *$ & $* *$ & hsa-miR-130a & $* * * *$ \\
\hline hsa-miR-130b-3p & hsa-mir-130b & $* *$ & $* * *$ & $*$ & hsa-miR-130b & $* * * *$ \\
\hline hsa-miR-134-5p & hsa-mir-134 & $* *$ & $* * * *$ & $* * *$ & hsa-miR-134 & $* * * *$ \\
\hline hsa-miR-139-5p & hsa-mir-139 & $* *$ & $* * *$ & $*$ & hsa-miR-139-5p & $* * *$ \\
\hline hsa-miR-138-5p & hsa-mir-138-1/2 & $* * *$ & $* *$ & $*$ & hsa-miR-138 & $* * *$ \\
\hline hsa-miR-140-3p & hsa-mir-140 & $* *$ & $* * * *$ & $* *$ & hsa-miR-140-3p & $* * * *$ \\
\hline hsa-miR-140-5p & hsa-mir-140 & $* *$ & $* * *$ & $*$ & hsa-miR-140-5p & $* * * *$ \\
\hline hsa-miR-142-5p & hsa-mir-142 & $* *$ & $* * *$ & $* *$ & hsa-miR-142-5p & $* * * *$ \\
\hline hsa-miR-143-3p & hsa-mir-143 & $* * *$ & $* * * *$ & $*$ & hsa-miR-143 & $* * * *$ \\
\hline hsa-miR-148b-3p & hsa-mir-148b & $* *$ & $* * *$ & $*$ & hsa-miR-148b & $* * * *$ \\
\hline hsa-miR-193a-3p & hsa-mir-193a & $* *$ & $* *$ & $*$ & hsa-miR-193a-3p & $* * * *$ \\
\hline hsa-miR-193a-5p & hsa-mir-193a & $* *$ & $* * * *$ & $*$ & hsa-miR-193a-5p & $* * * *$ \\
\hline hsa-miR-193b-3p & hsa-mir-193b & $* *$ & $* * *$ & $* *$ & hsa-miR-193b & $* *$ \\
\hline hsa-miR-199a-3p & hsa-mir-199a-1/199a-2/199b & $* *$ & $* * * * *$ & $* * *$ & hsa-miR-199a-3p & $* * * *$ \\
\hline hsa-miR-214-3p & hsa-mir-214 & $* *$ & $* * * * *$ & $* *$ & hsa-miR-214 & $* * * *$ \\
\hline hsa-miR-222-3p & hsa-mir-222 & $* *$ & $* * * * *$ & $*$ & hsa-miR-222 & $* *$ \\
\hline hsa-miR-223-3p & hsa-mir-223 & $* *$ & $* * * *$ & $* * *$ & hsa-miR-223 & $* *$ \\
\hline hsa-miR-335-5p & hsa-mir-335 & $* *$ & $* * * * *$ & $*$ & hsa-miR-335 & $* * * *$ \\
\hline hsa-miR-320a & hsa-mir-320a & $* * * * *$ & $* * * *$ & $* * *$ & hsa-miR-320 & $* * *$ \\
\hline hsa-miR-328-3p & hsa-mir-328 & $* *$ & $* *$ & $* * * *$ & hsa-miR-328 & $* * * *$ \\
\hline hsa-miR-345-5p & hsa-mir-345 & $* *$ & $* * *$ & $* * *$ & hsa-miR-345 & $* * * *$ \\
\hline hsa-miR-361-5p & hsa-mir-361 & $* *$ & $* * *$ & $*$ & hsa-miR-361-5p & $* * * *$ \\
\hline hsa-miR-370-3p & hsa-mir-370 & $* * *$ & $* * *$ & $* *$ & hsa-miR-370 & $* * * *$ \\
\hline hsa-miR-376c-3p & hsa-mir-376c & $* *$ & $* * * *$ & $* *$ & hsa-miR-376c & $* * * *$ \\
\hline hsa-miR-381-3p & hsa-mir-381 & $* *$ & $* * *$ & $*$ & hsa-miR-381 & $* * * *$ \\
\hline hsa-miR-382-5p & hsa-mir-382 & $* *$ & $* * * *$ & $*$ & hsa-miR-382 & $* * * *$ \\
\hline hsa-miR-410-3p & hsa-mir-410 & $* *$ & $* * *$ & $*$ & hsa-miR-410 & $* * * *$ \\
\hline hsa-miR-423-5p & hsa-mir-423 & $* * * *$ & $* * * * *$ & $* *$ & hsa-miR-423-5p & $* * * *$ \\
\hline hsa-miR-484 & hsa-mir-484 & $* *$ & $* * * * *$ & $*$ & hsa-miR-484 & $* * *$ \\
\hline hsa-miR-486-5p & hsa-mir-486-1 & $* * * *$ & $* * * *$ & $* * *$ & hsa-miR-486-5p & $* * * *$ \\
\hline hsa-miR-487b-3p & hsa-mir-487b & $* *$ & ***** & $*$ & hsa-miR-487b & $* * * *$ \\
\hline hsa-miR-495-3p & hsa-mir-495 & $* *$ & $* * * *$ & $*$ & hsa-miR-495 & $* * * *$ \\
\hline
\end{tabular}

\# only miRNA precursor was available for analysis

* global score of miRNA expression from weak $(*)$ to strong $(* * * *)$ 


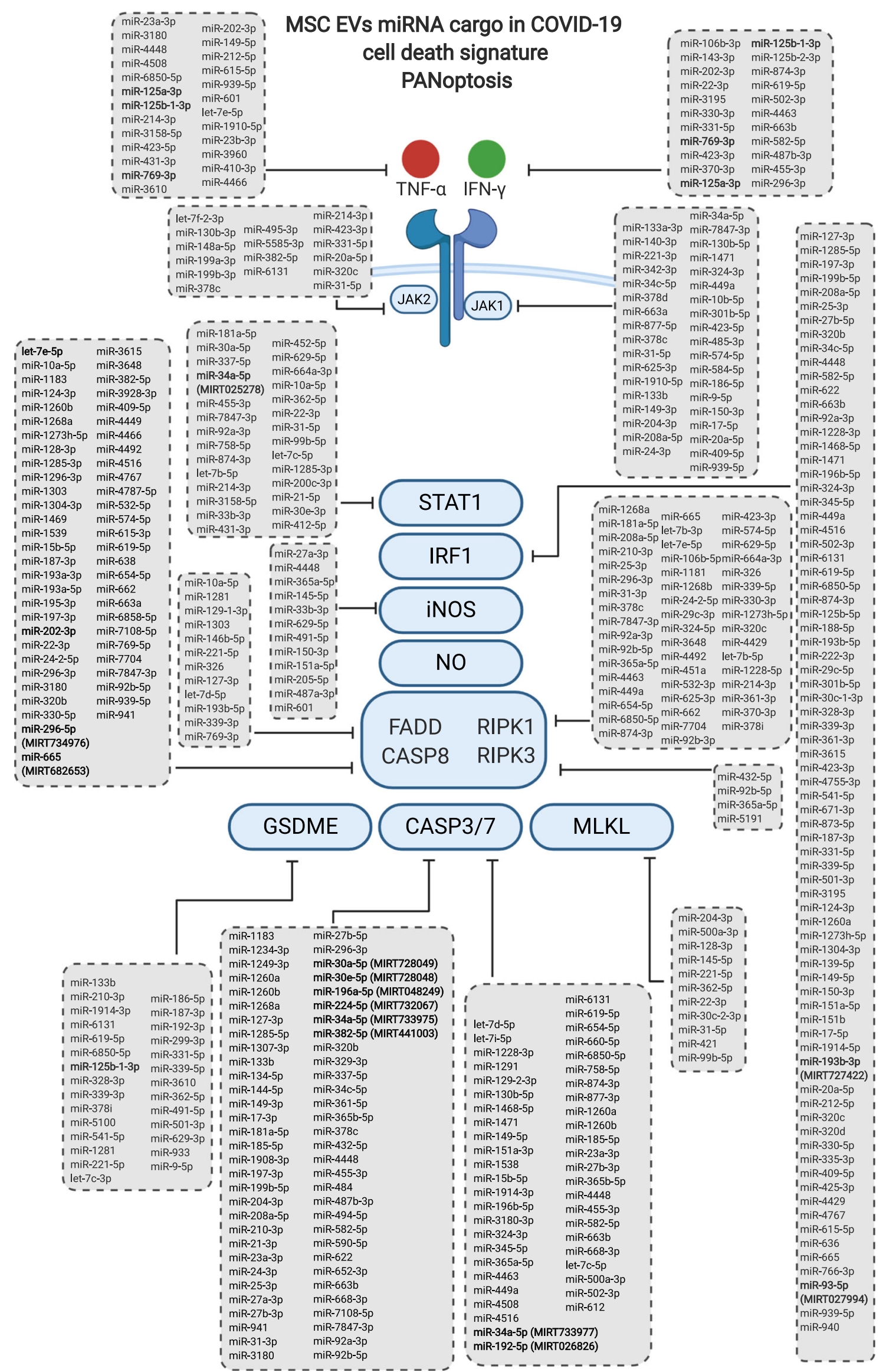


Fig. 1 Prediction of miRWalk for 3'UTR binding site of the 266 miRNAs from the MSC-derived EVs, shared in at least two datasets, in one or multiple targets of the PANoptosis cell death (pyroptosis, apoptosis and necrosis) key genes suggested by Karki et al.2020 [26]

The blockade of the cytokines and their receptors associated with hyperinflammation during COVID-19 can be a more rational targeted therapy [5]. For example, Tocilizumab is a monoclonal antibody anti-IL-6R, which blocks the IL-6/IL$6 \mathrm{R}$ complex formation [81, 82]. However, a randomized trial showed that the single target approach with the anti-IL-6R Tocilizumab did not show a significant improvement on COVID-19 patients outcome compared to standard care [83].

The approach using mesenchymal stem cells as therapy can be helpful once they have migration and homing ability, antiinflammatory, immunomodulatory, regenerative, proangiogenic and anti-fibrotic properties [33, 84]. Another relevant consideration is the increasing number of caesarian deliveries and aesthetic procedures, as liposuction, performed at the hospitals which increases the availability of discard materials such as umbilical cord and adipose tissue. These biological materials can be use as tissue source of MSC and before would be discarded and now can be reused. The homing ability of MSCs, in the case of ARDS due to COVID-19, may happen because the cells have membrane receptors to cytokines present in high levels, such as MCP-1(CCL2) and IL-8, chemoattracting the MSCs to the injury site $[85,86]$. Preclinical studies showed high efficacy of MSCs celltherapies allowing their clinical use [87]. Completed and ongoing clinical trials demonstrated the feasibility, safety, and tolerability of MSCs use in respiratory disorders, including ARDS [88]. Also, Emukah et al., reviewed the effects of MSC conditioned medium (MSC-CM) on many lung diseases and the results demonstrated that MSC-CM minimized the inflammation and was as similar as MSCs [89]. Further, it was identified that MSC-CM effects on cell proliferation, regeneration angiogenesis and others were partially due to the extracellular vesicles, drawing the scientific community attention to explore the EVs in translational medicine [39].

Despite of the establishment of the ISEV guidelines, in 2014 and updated in 2018, the studies with extracellular vesicles still present differences. As recently reviewed by Tieu et al., 2020, there are discrepancies according to the source, method of isolation, characterization of the EVs, nomenclature, treatment doses, administration route and experimental design. The authors also evidenced the scientific community interest showing the crescent curve of published papers since the first report of extracellular vesicle used as treatment for kidney injury model in 2009 [56, 90].

MSC-derived EVs are heterogeneous particles and its inner cargo can vary according to the source and physiological/ pathologic conditions at the time of EVs isolation [43]. In pathologic conditions, as viral infections, the EVs can carry in their cargo viral particles which could help to spread the pathogen throughout the body [91]. Therefore, when considering treatment, it is important use only cells derived from tissues of healthy donors, without any previous infectious event, preventing the viral transmission to treated patients. Also, differences in proteomics between MSC from adipose tissue, umbilical cord and bone marrow were already reported [92]. Moreover, differences about donors age shapes the EVs inner cargo and activity, except in MSCs from umbilical cord, presenting strongly immunomodulatory effects in healthy younger people [93]. Thus, we excluded the data of MSCderived EVs from elderly donors, using just healthy and young donors available data. Therefore, this higher immunomodulatory effect of MSC-derived EVs from healthy young donors with low immunogenicity, scalable production, storage for further use, could make it possible the creation of a "cell-free therapy bank". By using these healthy tissues discharged in medical procedures, it would turn this "multitarget treatment ready to use" available to patients, at the moment they arrive in the health system units, with high inflammatory and coagulant diseases.

The first bioinformatics analysis to predict microRNA targets was based on sequences complementarity between plant miRNAs and their targets. It has guided functional studies of several miRNAs [94]. Chauhan et al., through computational analysis, identified miRNAs that target Sars-CoV-2 viral genes (e.g. reducing the spike protein) avoiding the viral connection with the receptors in the host cells. Also, the authors identified miRNAs acting inside the host cells reducing the expression of receptors, preventing the entrance and viral replication, minimizing the spread of the infection [95]. MicroRNAs are small and unstable structures and possess a short half-life when are free in blood circulation and, for this reason, methods that could improve the half-life and delivery in specific sites improving their activity are necessary [96]. This highlights the benefits of use the EVs as a transportation carrier for this type of cargo.

As shown in Fig. 4, after the internalization of the EVs by the target cell (Fig. 4a), the miRNAs are released in the target cell cytoplasm (Fig. 4b) and, with assistance of enzyme complexes, the miRNA will attach in the target mRNA through a perfect or imperfect base-pairing in the 5'UTR, CD or 3'UTR gene regions (Fig. 4c). The imperfect attachment will result in an inhibition of the translation, while the perfect attachment will result in degradation of the mRNA [97].

We focused on this paper on the miRNAs related to the exacerbated cytokines and chemokines genes of severe COVID-19 patients reported elsewhere. Furthermore, we focused on analyze the interaction of the MSC-derived EVs miRNA cargo with the genes reported by Karki et al., 2020 [26] as responsible for cell death signature through PANopotis and the genes from the coagulation cascades. Our analysis 
MSC EVs miRNA cargo

in COVID-19 coagulopathy

Intrinsic pathway

Extrinsic pathway

let-7a-5p
let-7b-5p
let-7c-5p
let-7f-5p
miR-1224-5p
miR-125b-1-3p
miR-1268a

miR-378a-3p miR-378d miR-423-3p miR-423-5p miR-431-3p miR-431-3p miR-432-5p

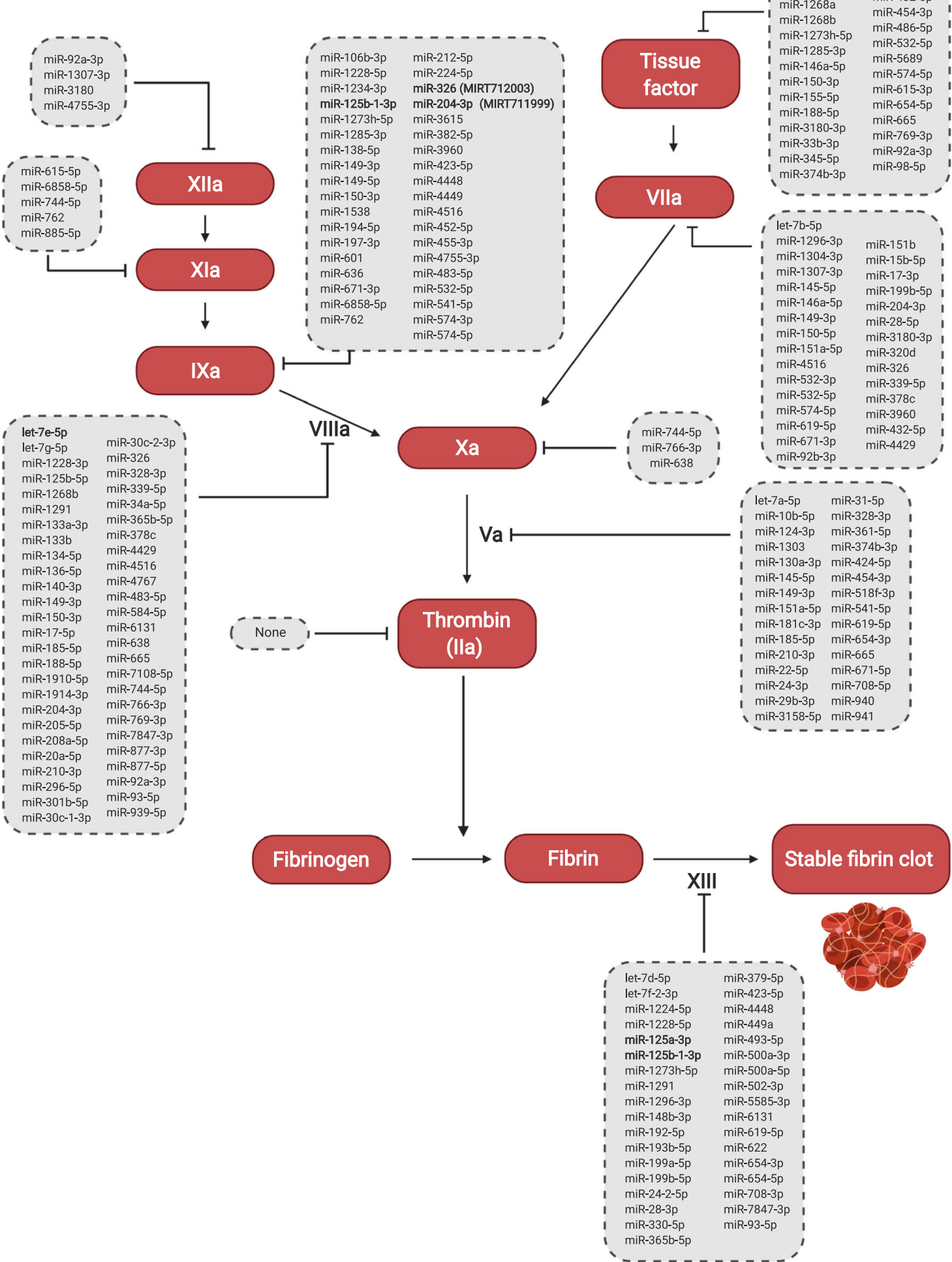


Fig. 2 Prediction of miRWalk for 3'UTR binding site of the 148 miRNAs from the MSC-derived EVs, shared in at least two datasets, in one or multiple targets of intrinsic and extrinsic coagulation cascades

results allow us to suggest that the miRNA from the MSCderived EVs has a therapeutic potential for investigation. As mentioned before, regardless the MSC-EVs have been derived from different tissue sources (adipose tissue, umbilical cord and bone marrow), there was an overlap of 58 miRNAs, among the four datasets of miRNA analyzed. The analysis of 3'UTR binding site target, from those miRNAs shared in at least two datasets, showed that 258 miRNAs could attach in this target region for all analyzed cytokines and chemokines. The extracellular vesicles carry not only different miRNAs, but also other molecules, characterizing the cargo as a heterogeneous material capable to interact with multitargets.
As mentioned, in pathological conditions, the EVs released can help to disseminate the disease throughout the organism, they can carry the pathogen responsible, or its structures inside the EVs. Although, based on the GSE12243 dataset analysis, the expression of the two receptors used by the Sars-CoV-2 to enter the host cell, toll like receptor 4 (TLR4) and Angiotensin-Converting enzyme 2 (ACE2), the TLR4 mRNA inside the EVs was not significant (Pearson's $\mathrm{r}=$ $0.763, p$ value $=0.0776$ ), as well as the ACE2 mRNA (Pearson's $r=-0.2717$ and $p$ value $=0.6025$ ). Based on these results, there is not enough mRNA to produce these proteins in the EVs. Therefore, MSC-derived EVs, unlike their MSCs parental cells, would not be involved in the spread of the SarsCoV-2 and wouldn't increase the COVID-19 development.

As highlighted in Sup.Table 4, Figs. 1 and 2, one miRNA binds to multiple mRNAs. For example, miR-125a-3p binds to the portion 3'UTR of IL2, CXCL10, IL7, IL10 and IL15.

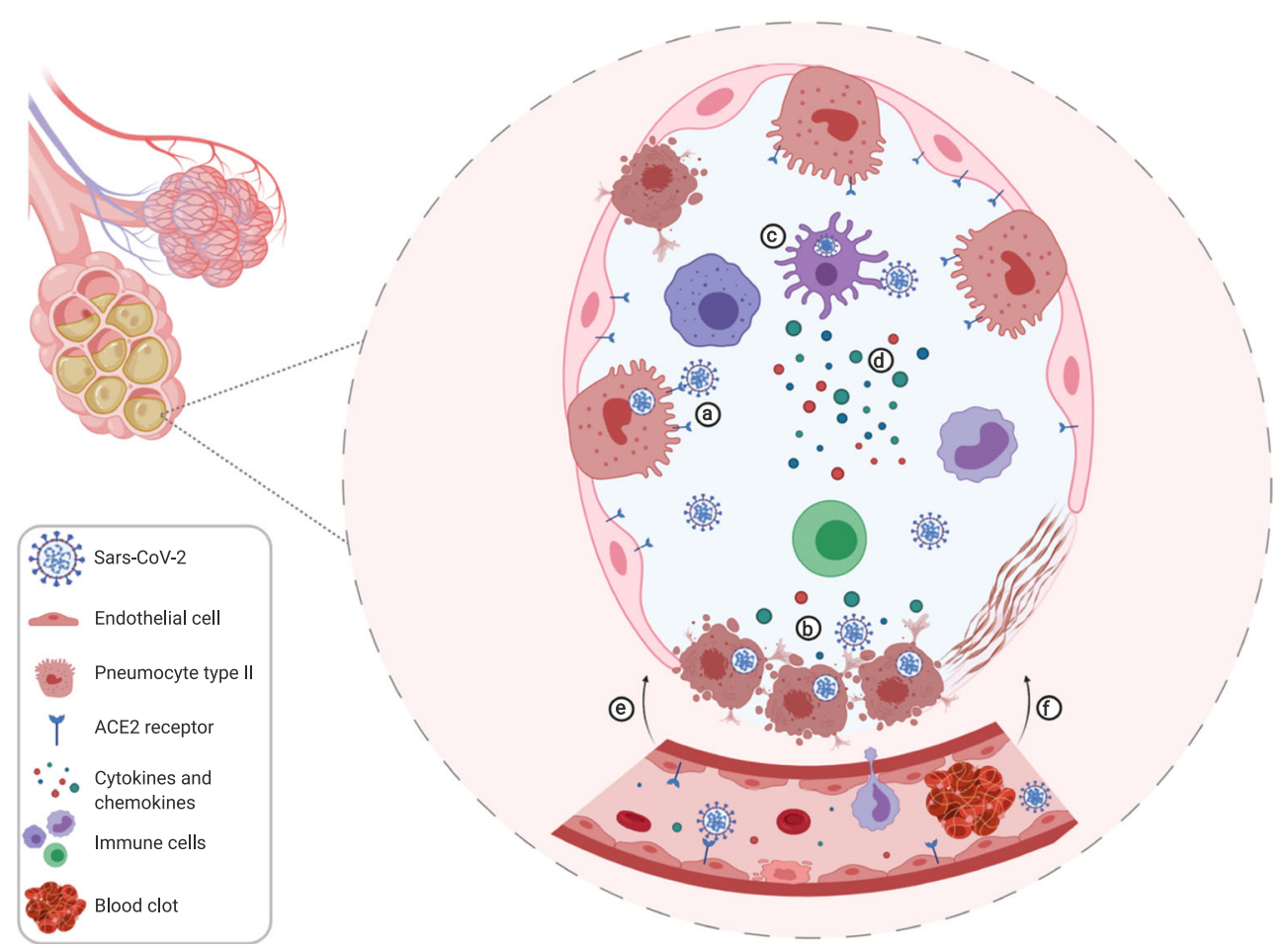

Fig. 3 A representative alveoli cross-section with adjacent blood capillary presenting the events of COVID-19 development. (a) The ReceptorBinding Domain (RBD) of Sars-CoV-2 binds to the ACE2 receptor in the membrane of pneumocytes type II, endothelial cells and others. The viral spike protein is cleveaged by Transmembrane Protease Serine 2 (TMPRSS2), a protease present in the surface of the host cells. (b) Viral replication is performed originating new copies to be released in the extracellular environment. Also, the vírus induce the cell death by PANoptosis (pyroptosis, apoptosis and necrosis) causing the release of damage associated molecular patterns (DAMPs), which will be recognized by alveolar epithelial cells and alveolar macrophages with the pattern recognition receptors (PRRs). (c) The antigen recognition will trigger an immune response where dendritic cells, monocytes, macrophages, neutrophils and $\mathrm{T}$ cells will be atracted to the infection site. These cells have the stimuli to express tissue factor in their membrane starting coagulation activation (d) ICU patients with severe COVID-19 present higher baseline levels of IL-6, IL-1 $\beta$, TNF- $\alpha$, IL-2, IL-7, IL-8, IL-9, IL-10, IL17, G-CSF, MCP-1 (CCL2), MIP-1 $\alpha$ (CCL3), MCP-3 (CCL7) and CXCL10 (IP-10), IL-18, IL-33, IL1- $\alpha$, IL-15. (e) Direct cell death, caused by Sars-CoV-2, and the inflammatory cell death increase vascular permeability and cause fluid efflux from blood vessels and capilaries into the lungs interfering in the gas exchange and consequently damaging lung tissue. Also, blood clot formation interfere in the organs homeaostasis. Thus, the patient clinically progress to an acute respiratory distress syndrome requiring mechanical ventilation. (f) Areas of consolidation by fibroblastic proliferation and deposition of extracellular matrix and fibrin in the alveolar spaces can be detected by CT scans 


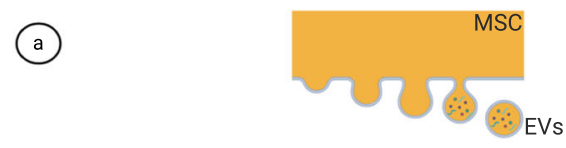

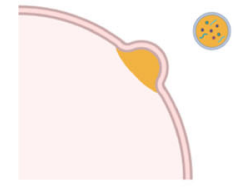

Direct fusion

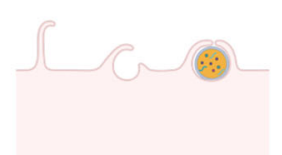

Macropinocytosis



Endocytosis
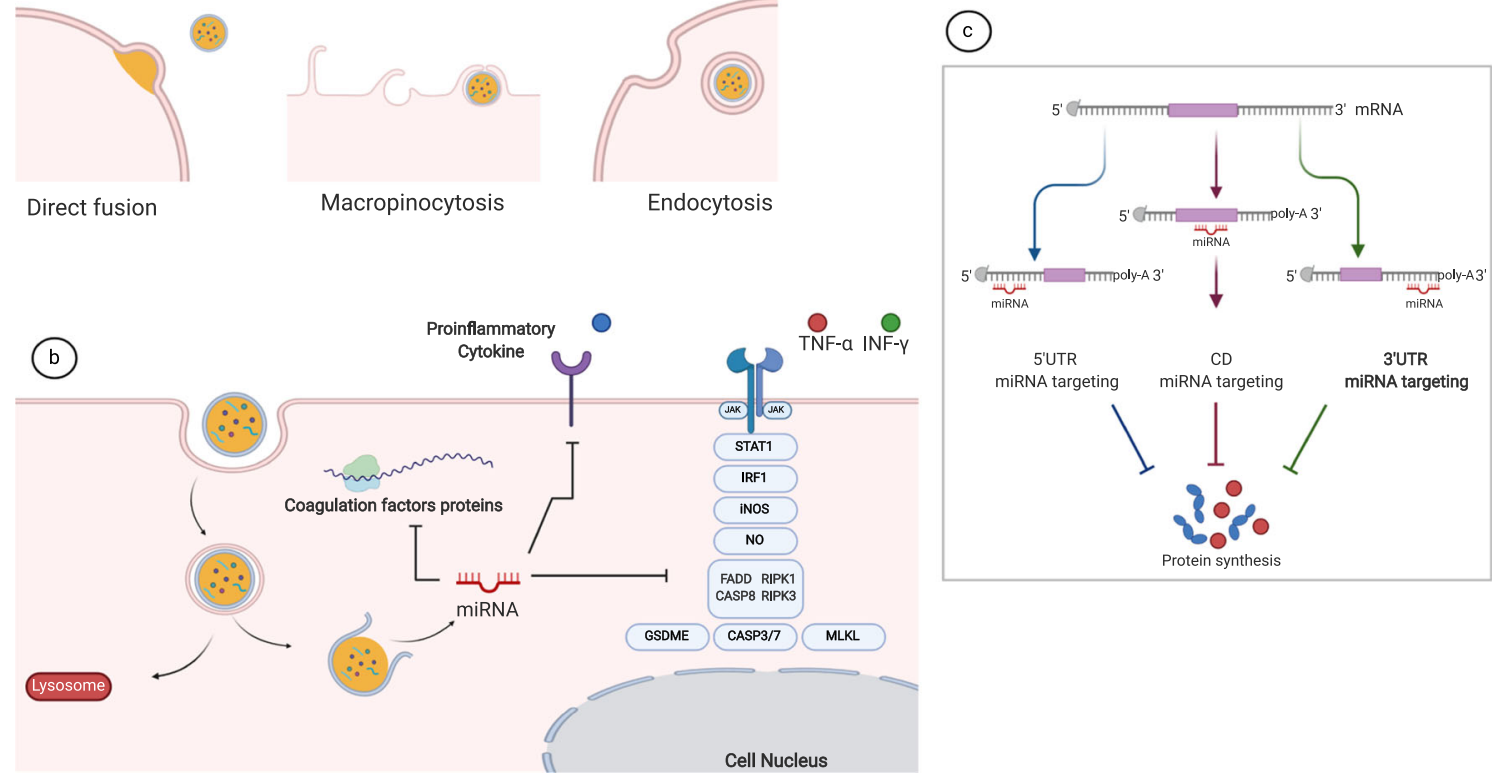

Cell Nucleus

Fig. 4 Mechanisms of extracellular vesicles release, internalization and action of miRNA cargo in the target cell genes. (a) The internalization of the EVs in the target cell occurs by multiple mechanisms, such as membrane direct fusion, macropinocytosis and endocytosis. (b) After EVs internalization, through endolysosomal pathway, the lipidic bilayer of the EVs are degraded and their cargo is released in the cell cytoplasm allowing the performance of each cargo specific action. (c) In mammalians, the miRNA binds through perfect and imperfect basepairing on different regions of target mRNA 3'UTR, repressing translation of the protein
Moreover, miR-125a-3p binds to the 3'UTR region of TNF, IFN and binds also to the 3'UTR of Factor XIII gene. This multitargeted approach could minimize cell death, alleviate the systemic inflammation and coagulation disturbs in severe COVID-19 patients improving their clinical outcome. Another isoform, expressed in the four analyzed miRNA datasets, is the miR-125b-1-3p which targets the 3'UTR region of the CXCL10, IL17A, IL10, CCL3, IL18 and IL33 and targets the 3'UTR region of TNF, IFN, and GSDME genes. In addition, miR-125b-1-3p also binds to the 3'UTR region of Factor III, IX and XIII. One study performed by Fujii and collaborators showed the Graft-Versus-Host Disease (GVHD) amelioration in vitro and in vivo through, at least partially, by the multitarget potential of BM-MSC-derived EVs miRNA content, including miR-125a-3p [98]. Two other miRNAs, miR-769-3p and miR-202-3p, may attenuate the cell death avoiding tissue damage by targeting synergistically the 3'UTR region of the TNF e IFN genes inhibiting their protein translation.

The target of IL-1 and IL- 6 pathways could attenuate the coagulation activation manifested by admitted severe COVID-19 ICU patients [72, 75, 99]. Thus, the miRNA, highly expressed in the four analyzed datasets, let-7e-5p could promote this action by binding in the 3'UTR region of IL1A, IL1B, IL6R, IL15, IL10 and CSF3 genes. In addition, the let-7e-5p binds to the 3'UTR region of TNF, RIPK1 and CASP8 genes that are participants of the cell death signature pathway. In addition, it directly targets the 3'UTR portion of Factor VIII gene from the coagulation cascade.

Let-7 was firstly found in C. elegans and it was the second miRNA discovered [100]. The functions of this microRNA family are the most studied. There are reports in the literature about their relation with inflammation [101, 102], cancer [103] and other conditions. Among our 27 experimentally validated miRNAs, 7 target the IL-6R of which 3 are members of the let-7 family. This relation is corroborated by the literature, as Sung et al. (2018) showed that in a coculture of MSCs derived from bone marrow and prostate cancer cells, the loss of let-7 leads to an upregulation of IL-6 expression [104]. Moreover, Di et al.(2020) evaluated the let-7 in airway remodeling in chronic obstructive pulmonary disease (COPD) via the regulation of IL- 6 mRNA by targeting and silencing its 3'UTR region. Also, let-7 works as a regulator of myofibroblast differentiation, through the regulation of this cytokine expression [105].

Some studies suggest that using an approach with a combination of treatments, or a multitarget therapy, versus monotherapy is preferable $[106,107]$. Several reviews and reports already discussed the potential of investigation of MSCderived EVs and its cargo, particularly miRNA, in COVID- 
19 as well as other lung and heart injuries [41, 108-114]. Based on our analysis, it is possible to suggest that the multitarget characteristic of the MSC-derived EVs miRNA cargo could be an advantage, in comparison to therapies with a single target, such as Tocilizumab or Anakira (anti-IL1R). These therapies are used to decrease inflammatory biomarkers, due to interactions with multiple pathways. They improve the patient outcome by minimizing tissue damage and mitigating the coagulation activation and thrombi formation. Although, more studies of fully characterization, evaluation and functionality of the MSC-EVs content are required to confirm their benefits.

The therapeutically potential of the MSC-derived EVs against COVID-19 and other high inflammatory lung injuries is corroborated by other reports showing important results such as: the polarization of macrophages M1 (proinflammatory) to a M2 (anti-inflammatory) phenotype, activation and regulation of $\mathrm{T}$ cells [115]; MSC-derived exosomes prevent the recruitment of monocytes and reduces the secretion of pro-fibrotic IL10 and TGF- $\beta$ by these cells in the lung of silica-exposed mice [55]. Also, the use of MSCderived EVs ACE2+ to compete with Sars-CoV-2 to the host cells receptor binding [116]. Therefore, the miRNA cargo of the MSC-derived EVs as therapy could be useful, not only in COVID-19, but also in other viral infections that present high levels of inflammatory cytokines, as influenza.

\section{Conclusion}

The analysis of bioinformatics prediction showed that miRNA inner cargo of MSC-derived EVs may attenuate the production of excessive inflammatory cytokines and chemokines, coagulation cascade and cell death by multitargeting the 3'UTR region of several mRNA. Regardless the differences among tissue sources, there was miRNA overlap. Thus, even without an establishment of which tissue is the best source to extract the mesenchymal stem cells, or methods of the EVs isolation and characterization, the positive effect against the exacerbated inflammatory agents and coagulation disturbs present in severe COVID-19 may be achieved. Multiple clinical trials using MSC against COVID-19 are currently ongoing, some of them already are completed and showed the feasibility, safety and low adverse effects in COVID-19 treated patients. As the extracellular vesicles share some intrinsic characteristics with their parental cells and have the advantage to be small sized, non-proliferation activity and low immunogenicity more published outcomes of currently ongoing randomized and future clinical trials, with a larger number of enrolled patients, testing exosomes in COVID-19 are well awaited.

The research for a specific antiviral to Sars-CoV-2 and the development of a functional vaccine are the goals in this pandemic period. However, a long period can be taken until the achievement of satisfactory results and an equal distribution worldwide. Therefore, the development of anti-inflammatory and anticoagulant therapies, such as the MSC-derived EVs and its inner natural cargo from healthy donors, deserves attention and investigation, aiming the reduction of death rates due to the COVID-19 around the world. Besides that, there is a possibility to create in health units, a cell-free therapy bank that could provide treatment for immediate application that could also benefit other patients, with high inflammatory and coagulant diseases. Furthermore, more studies of full characterization and evaluation of the mesenchymal stem cells derived extracellular vesicles and its cargo functions in COVID-19, as well as in other infectious events, are still necessary.

Supplementary Information The online version contains supplementary material available at https://doi.org/10.1007/s12015-021-10122-0.

Acknowledgements The authors would like to thank Dr. Cristina B. C. Bonorino for her critical reading and suggestions to the manuscript and by the coordination of the CAPES grant "FÁRMACOS E IMUNOLOGIA" $\mathrm{n}^{\circ} 11 / 2020$. Schematic representations were created with BioRender. com.

Authors' Contribution ICS - data analysis and manuscript writing. APS - data analysis and manuscript writing. MW - reviewed the manuscript.

Funding Iago C. Schultz is a recipient of a $\mathrm{PhD}$ scholarship of COMBATE-COVID 1694577P by Coordenação de Aperfeiçoamento de Pessoal de Nível Superior - Brasil (CAPES). Ana P.S. Bertoni is recipient of a postdoctoral Scholarship from CAPES/PNPD (Programa Nacional de Pós-Doutorado) and Márcia R. Wink is recipient of research 1D level research fellowship (PQ) from Conselho Nacional de Desenvolvimento Científico e Tecnológico (CNPq). This study was financed in part by the CNPq grant "PESQUISAS DE INOVAÇÃO EM SAÚDE 2018" (Process 441575/2018-8).

Data Availability Not applicable.

Code Availability Not applicable

\section{Compliance with Ethical Standards}

Conflict of Interest The authors declared no conflict of interest.

Ethics Approval Not applicable.

Consent to Participate Not applicable.

Consent for Publication Not applicable.

\section{References}

1. Zhu, N., Zhang, D., Wang, W., Li, X., Yang, B., Song, J., Zhao, X., Huang, B., Shi, W., Lu, R., Niu, P., Zhan, F., Ma, X., Wang, 
D., Xu, W., Wu, G., Gao, G. F., Tan, W., \& China Novel Coronavirus Investigating and Research Team. (2020). A novel coronavirus from patients with pneumonia in China, 2019. The New England Journal of Medicine, 382(8), 727-733. https://doi. org/10.1056/NEJMoa2001017.

2. Lu, R., Zhao, X., Li, J., Niu, P., Yang, B., Wu, H., Wang, W., Song, H., Huang, B., Zhu, N., Bi, Y., Ma, X., Zhan, F., Wang, L., Hu, T., Zhou, H., Hu, Z., Zhou, W., Zhao, L., Chen, J., Meng, Y., Wang, J., Lin, Y., Yuan, J., Xie, Z., Ma, J., Liu, W. J., Wang, D., Xu, W., Holmes, E. C., Gao, G. F., Wu, G., Chen, W., Shi, W., \& Tan, W. (2020). Genomic characterisation and epidemiology of 2019 novel coronavirus: Implications for virus origins and receptor binding. Lancet., 395(10224), 565-574. https://doi.org/10. 1016/S0140-6736(20)30251-8.

3. World Health Organization. Naming the coronavirus disease (COVID-19) and the virus that causes it. World Heal Organ. 2020:1. https://www.who.int/emergencies/diseases/novelcoronavirus-2019/technical-guidance/naming-the-coronavirusdisease-(covid-2019)-and-the-virus-that-causes-it.

4. Woo, P. C. Y., Lau, S. K. P., Huang, Y., \& Yuen, K. Y. (2009). Coronavirus diversity, phylogeny and interspecies jumping. Experimental Biology and Medicine, 234(10), 1117-1127. https://doi.org/10.3181/0903-MR-94.

5. Felsenstein S, Herbert JA, Mcnamara PS, Hedrich CM. COVID19: Immunology and treatment options. Clin Immunol. 2020;(January).

6. Zhou, P., Lou, Y. X., Wang, X. G., et al. (2020). A pneumonia outbreak associated with a new coronavirus of probable bat origin. Nature, 579(7798), 270-273. https://doi.org/10.1038/s41586020-2012-7.

7. Hamming, I., Timens, W., Bulthuis, M. L. C., Lely, A. T., Navis, G. J., \& van Goor, H. (2004). Tissue distribution of ACE2 protein, the functional receptor for SARS coronavirus. A first step in understanding SARS pathogenesis. The Journal of Pathology, 203(2), 631-637. https://doi.org/10.1002/path.1570.

8. Shang J, Wan Y, Luo C, et al. Cell entry mechanisms of SARSCoV-2. Proc Natl Acad Sci U S A. 2020;117(21). doi:https://doi. org/10.1073/pnas.2003138117

9. Frydman, G. H., Streiff, M. B., Connors, J. M., \& Piazza, G. (2020). The potential role of coagulation factor Xa in the pathophysiology of COVID-19: A role for anticoagulants as multimodal therapeutic agents. TH Open., 04(04), e288-e299. https://doi. org/10.1055/s-0040-1718415.

10. Hoffmann, M., Kleine-Weber, H., Schroeder, S., et al. (2020). SARS-CoV-2 Cell Entry Depends on ACE2 and TMPRSS2 and Is Blocked by a Clinically Proven Protease Inhibitor. Cell, 181(2), 271-280.e8. https://doi.org/10.1016/j.cell.2020.02.052.

11. Guan WJ, Liang WH, Zhao Y, et al. Comorbidity and its impact on 1,590 patients with Covid-19 in China: A nationwide analysis. Eur Respir J. 2020;55(5). doi:https://doi.org/10.1183/13993003. 00547-2020

12. Yang, J., Zheng, Y., Gou, X., Pu, K., Chen, Z., Guo, Q., Ji, R., Wang, H., Wang, Y., \& Zhou, Y. (2020). Prevalence of comorbidities and its effects in coronavirus disease 2019 patients: A systematic review and meta-analysis. International Journal of Infectious Diseases, 94, 91-95. https://doi.org/10.1016/j.ijid. 2020.03.017.

13. Huang, C., Wang, Y., Li, X., Ren, L., Zhao, J., Hu, Y., Zhang, L., Fan, G., Xu, J., Gu, X., Cheng, Z., Yu, T., Xia, J., Wei, Y., Wu, W., Xie, X., Yin, W., Li, H., Liu, M., Xiao, Y., Gao, H., Guo, L., Xie, J., Wang, G., Jiang, R., Gao, Z., Jin, Q., Wang, J., \& Cao, B. (2020). Clinical features of patients infected with 2019 novel coronavirus in Wuhan. China. Lancet., 395(10223), 497-506. https://doi.org/10.1016/S0140-6736(20)30183-5.
14. Liu Y, Sun W, Li J, et al. Clinical features and progression of acute respiratory distress syndrome in coronavirus disease 2019 . 2020;681. doi:https://doi.org/10.1101/2020.02.17.20024166.

15. Long, X., Zhang, Z., Zou, W., Ling, J., Li, D., Jing, L., Yu, S., Zou, X., Bian, Y., Wu, W., Li, S., \& Fang, M. (2020). Coagulopathy of patients with covid-19 is associated with infectious and inflammatory markers. Risk Manag Healthc Policy., 13, 1965-1975. https://doi.org/10.2147/RMHP.S268238.

16. Guan, W., Ni, Z., Hu, Y., Liang, W. H., Ou, C. Q., He, J. X., Liu, L., Shan, H., Lei, C. L., Hui, D. S. C., du, B., Li, L. J., Zeng, G., Yuen, K. Y., Chen, R. C., Tang, C. L., Wang, T., Chen, P. Y., Xiang, J., Li, S. Y., Wang, J. L., Liang, Z. J., Peng, Y. X., Wei, L., Liu, Y., Hu, Y. H., Peng, P., Wang, J. M., Liu, J. Y., Chen, Z., Li, G., Zheng, Z. J., Qiu, S. Q., Luo, J., Ye, C. J., Zhu, S. Y., Zhong, N. S., \& China Medical Treatment Expert Group for Covid-19. (2020). Clinical characteristics of coronavirus disease 2019 in China. The New England Journal of Medicine, 382(18), 17081720. https://doi.org/10.1056/NEJMoa2002032.

17. Ranieri, V. M., Rubenfeld, G. D., Thompson, B. T., et al. (2012). Acute respiratory distress syndrome: The Berlin definition. JAMA - J Am Med Assoc., 307(23), 2526-2533. https://doi.org/10.1001/ jama.2012.5669.

18. Gupta, S., Hayek, S. S., Wang, W., Chan, L., Mathews, K. S., Melamed, M. L., Brenner, S. K., Leonberg-Yoo, A., Schenck, E. J., Radbel, J., Reiser, J., Bansal, A., Srivastava, A., Zhou, Y., Sutherland, A., Green, A., Shehata, A. M., Goyal, N., Vijayan, A., Velez, J. C. Q., Shaefi, S., Parikh, C. R., Arunthamakun, J., Athavale, A. M., Friedman, A. N., Short, S. A. P., Kibbelaar, Z. A., Abu Omar, S., Admon, A. J., Donnelly, J. P., Gershengorn, H. B., Hernán, M. A., Semler, M. W., Leaf, D. E., \& STOP-COVID Investigators. (2020). Factors associated with death in critically ill patients with coronavirus disease 2019 in the US. JAMA Internal Medicine, 02115, 1-11. https://doi.org/10.1001/jamainternmed. 2020.3596.

19. Zhou, F., Yu, T., Du, R., et al. (2020). Clinical course and risk factors for mortality of adult inpatients with COVID-19 in Wuhan, China: A retrospective cohort study. Lancet., 395(10229), 1054 1062. https://doi.org/10.1016/S0140-6736(20)30566-3.

20. Tang, N., Li, D., Wang, X., \& Sun, Z. (2020). Abnormal coagulation parameters are associated with poor prognosis in patients with novel coronavirus pneumonia. Journal of Thrombosis and Haemostasis, 18(4), 844-847. https://doi.org/10.1111/jth.14768.

21. Tang, N., Bai, H., Chen, X., Gong, J., Li, D., \& Sun, Z. (2020). Anticoagulant treatment is associated with decreased mortality in severe coronavirus disease 2019 patients with coagulopathy. Journal of Thrombosis and Haemostasis, 18(5), 1094-1099. https://doi.org/10.1111/jth.14817.

22. Liu, Y., Yang, Y., Zhang, C., Huang, F., Wang, F., Yuan, J., Wang, Z., Li, J., Li, J., Feng, C., Zhang, Z., Wang, L., Peng, L., Chen, L., Qin, Y., Zhao, D., Tan, S., Yin, L., Xu, J., Zhou, C., Jiang, C., \& Liu, L. (2020). Clinical and biochemical indexes from 2019-nCoV infected patients linked. Science China. Life Sciences, 63(3), 364-374. https://doi.org/10.1007/s11427-020-1643-8.

23. Can $\mathrm{A}, \mathrm{Coskun} \mathrm{H}$. The rationale of using mesenchymal stem cells in patients with COVID-19-related acute respiratory distress syndrome: What to expect. Stem Cells Transl Med. 2020;(April):116. doi:https://doi.org/10.1002/sctm.20-0164

24. Rogers, C. J., Harman, R. J., Bunnell, B. A., Schreiber, M. A., Xiang, C., Wang, F. S., Santidrian, A. F., \& Minev, B. R. (2020). Rationale for the clinical use of adipose-derived mesenchymal stem cells for COVID-19 patients. Journal of Translational Medicine, 18(1), 1-19. https://doi.org/10.1186/s12967-02002380-2.

25. Leisman DE, Ronner L, Pinotti R, et al. Cytokine elevation in severe and critical COVID-19: a rapid systematic review, metaanalysis, and comparison with other inflammatory syndromes. 
Lancet Respir Med. 2020;2600(20). doi:https://doi.org/10.1016/ s2213-2600(20)30404-5

26. Karki R, Sharma BR, Tuladhar S, Williams EP, Zalduondo L. COVID-19 cytokines and the hyperactive immune response : Synergism of TNF- $\alpha$ and IFN- $\gamma$ in triggering inflammation, tissue damage, and death. 2020.

27. Thachil, J., Tang, N., Gando, S., Falanga, A., Cattaneo, M., Levi, M., Clark, C., \& Iba, T. (2020). ISTH interim guidance on recognition and management of coagulopathy in COVID-19. Journal of Thrombosis and Haemostasis, 18(5), 1023-1026. https://doi.org/ 10.1111/jth.14810.

28. Porfidia, A., \& Pola, R. (2020). Venous thromboembolism and heparin use in COVID-19 patients: Juggling between pragmatic choices, suggestions of medical societies and the lack of guidelines. Journal of Thrombosis and Thrombolysis, 50(1), 68-71. https://doi.org/10.1007/s11239-020-02125-4.

29. Beun, R., Kusadasi, N., Sikma, M., Westerink, J., \& Huisman, A. (2020). Thromboembolic events and apparent heparin resistance in patients infected with SARS-CoV-2. International Journal of Laboratory Hematology, 42(S1), 19-20. https://doi.org/10.1111/ ijlh.13230.

30. Trunfio, M., Salvador, E., Cabodi, D., Marinaro, L., Alcantarini, C., Gaviraghi, A., Trentalange, A., Lipani, F., Sciascia, S., Roccatello, D., Bonora, S., di Perri, G., Calcagno, A., \& eCOVID Study group. (2020). Anti-Xa monitoring improves low-molecular-weight heparin effectiveness in patients with SARS-CoV-2 infection. Thrombosis Research, 196(January), 432-434. https://doi.org/10.1016/j.thromres.2020.09.039.

31. Li, H., Zhou, Y., Zhang, M., Wang, H., \& Zhao, Q. (2020). Updated approaches against SARS-CoV-2. Antimicrobial Agents and Chemotherapy, 64(6), 1-7.

32. Viswanathan, S., Shi, Y., Galipeau, J., Krampera, M., Leblanc, K., Martin, I., Nolta, J., Phinney, D. G., \& Sensebe, L. (2019). Mesenchymal stem versus stromal cells: International Society for Cell \& gene therapy (ISCT®) mesenchymal stromal cell committee position statement on nomenclature. Cytotherapy., 21(10), 1019-1024. https://doi.org/10.1016/j.jcyt.2019.08.002.

33. Leng, Z., Zhu, R., Hou, W., et al. (2020). Transplantation of ACE2-Mesenchymal stem cells improves the outcome of patients with covid-19 pneumonia. Aging and Disease, 11(2), 216-228. https://doi.org/10.14336/AD.2020.0228.

34. Liang, B., Chen, J., Li, T., Wu, H., Yang, W., Li, Y., Li, J., Yu, C., Nie, F., Ma, Z., Yang, M., Xiao, M., Nie, P., Gao, Y., Qian, C., \& $\mathrm{Hu}, \mathrm{M}$. (2020). Clinical remission of a critically ill COVID-19 patient treated by human umbilical cord mesenchymal stem cells: A case report. Medicine (Baltimore), 99(31), e21429. https://doi. org/10.1097/MD.0000000000021429.

35. Sánchez-Guijo F, García-Arranz M, López-Parra M, et al. Adipose-derived mesenchymal stromal cells for the treatment of patients with severe SARS-CoV-2 pneumonia requiring mechanical ventilation. A proof of concept study. EClinicalMedicine. 2020;25. doi:https://doi.org/10.1016/j.eclinm.2020.100454

36. Sengupta, V., Sengupta, S., Lazo, A., Woods, P., Nolan, A., \& Bremer, N. (2020). Exosomes derived from bone marrow mesenchymal stem cells as treatment for severe COVID-19. Stem Cells and Development, 29(12), 747-754. https://doi.org/10.1089/scd. 2020.0080 .

37. Théry C, Witwer KW, Aikawa E, et al. Minimal information for studies of extracellular vesicles 2018 (MISEV2018): a position statement of the International Society for Extracellular Vesicles and update of the MISEV2014 guidelines. $J$ Extracell Vesicles. 2018;7(1). doi:https://doi.org/10.1080/20013078.2018.1535750

38. Van Deun, J., Mestdagh, P., Agostinis, P., et al. (2017). EVTRACK: Transparent reporting and centralizing knowledge in extracellular vesicle research. Nature Methods, 14(3), 228-232. https://doi.org/10.1038/nmeth.4185.
39. Wiklander OPB, Brennan M, Lötvall J, Breakefield XO, Andaloussi SEL. Advances in therapeutic applications of extracellular vesicles. Science Translational Medicine. 2019;11(492). doi:https://doi.org/10.1126/scitranslmed.aav8521

40. Hassanpour, M., Rezaie, J., Nouri, M., \& Panahi, Y. (2020). The role of extracellular vesicles in COVID-19 virus infection. Infection, Genetics and Evolution, 85, 104422. https://doi.org/10. 1016/j.meegid.2020.104422.

41. El Andaloussi, S., Mäger, I., Breakefield, X. O., \& Wood, M. J. A. (2013). Extracellular vesicles: Biology and emerging therapeutic opportunities. Nature Reviews. Drug Discovery, 12(5), 347-357. https://doi.org/10.1038/nrd3978.

42. Bulut, Ö., \& Gürsel, İ. (2020). Mesenchymal stem cell derived extracellular vesicles: Promising immunomodulators against autoimmune, autoinflammatory disorders and SARS-CoV-2 infection. Turkish Journal of Biology, 44(Special issue 1), 273-282. https:// doi.org/10.3906/biy-2002-79.

43. O'Brien, K., Breyne, K., Ughetto, S., Laurent, L. C., \& Breakefield, X. O. (2020). RNA delivery by extracellular vesicles in mammalian cells and its applications. Nature Reviews. Molecular Cell Biology, 21, 585-606. https://doi.org/10.1038/ s41580-020-0251-y.

44. Öztürk S, Elçin AE, Koca A, Elçin YM. Therapeutic applications of stem cells and extracellular vesicles in emergency care: Futuristic perspectives. Stem Cell Reviews and Reports. 2020. doi:https://doi.org/10.1007/s12015-020-10029-2.

45. Shah, T. G., Predescu, D., \& Predescu, S. (2019). Mesenchymal stem cells-derived extracellular vesicles in acute respiratory distress syndrome: A review of current literature and potential future treatment options. Clinical and Translational Medicine, 8(1), 25. https://doi.org/10.1186/s40169-019-0242-9.

46. Shetty, A. K. (2020). Mesenchymal stem cell infusion shows promise for combating coronavirus (COVID-19)-induced pneumonia. Aging and Disease, 11(2), 462-464. https://doi.org/10. 14336/AD.2020.0301.

47. Gardin, C., Ferroni, L., Chachques, J. C., \& Zavan, B. (2020). Could mesenchymal stem cell-derived exosomes be a therapeutic option for critically Ill COVID-19 patients? Journal of Clinical Medicine, 9(9), 2762. https://doi.org/10.3390/jcm9092762.

48. Bartel, D. P. (2009). MicroRNAs: Target recognition and regulatory functions. Cell., 136(2), 215-233. https://doi.org/10.1016/j. cell.2009.01.002.

49. Bartoszewski, R., Dabrowski, M., Jakiela, B., Matalon, S., Harrod, K. S., Sanak, M., \& Collawn, J. F. (2020). SARS-CoV2 may regulate cellular responses through depletion of specific host miRNAs. Am J Physiol Cell Mol Physiol., 319(3), L444L455. https://doi.org/10.1152/ajplung.00252.2020.

50. Zhang, K., Zhang, X., Cai, Z., Zhou, J., Cao, R., Zhao, Y., Chen, Z., Wang, D., Ruan, W., Zhao, Q., Liu, G., Xue, Y., Qin, Y., Zhou, B., Wu, L., Nilsen, T., Zhou, Y., \& Fu, X. D. (2018). A novel class of microRNA-recognition elements that function only within open reading frames. Nature Structural \& Molecular Biology, 25(11), 1019-1027. https://doi.org/10.1038/s41594018-0136-3.

51. Fang, S., Xu, C., Zhang, Y., Xue, C., Yang, C., Bi, H., Qian, X., Wu, M., Ji, K., Zhao, Y., Wang, Y., Liu, H., \& Xing, X. (2016). Umbilical cord-derived mesenchymal stem cell-derived Exosomal MicroRNAs suppress Myofibroblast differentiation by inhibiting the transforming growth factor- $\beta / \mathrm{SMAD} 2$ pathway during wound healing. Stem Cells Translational Medicine, 5(10), 1425-1439. https://doi.org/10.5966/sctm.2015-0367.

52. Qian, X., Xu, C., Fang, S., Zhao, P., Wang, Y., Liu, H., Yuan, W., \& Qi, Z. (2016). Exosomal MicroRNAs derived from umbilical mesenchymal stem cells inhibit hepatitis $C$ virus infection. Stem Cells Translational Medicine, 5(9), 1190-1203. https://doi.org/ 10.5966/sctm.2015-0348. 
53. Umezu, T., Imanishi, S., Yoshizawa, S., Kawana, C., Ohyashiki, J. H., \& Ohyashiki, K. (2019). Induction of multiple myeloma bone marrow stromal cell apoptosis by inhibiting extracellular vesicle miR-10a secretion. Blood Advances, 3(21), 3228-3240. https://doi.org/10.1182/bloodadvances.2019000403.

54. Umezu, T., Imanishi, S., Azuma, K., Kobayashi, C., Yoshizawa, S., Ohyashiki, K., \& Ohyashiki, J. H. (2017). Replenishing exosomes from older bone marrow stromal cells with miR-340 inhibits myeloma-related angiogenesis. Blood Advances, 1(13), 812-823. https://doi.org/10.1182/bloodadvances.2016003251.

55. Phinney, D. G., Di Giuseppe, M., Njah, J., et al. (2015). Mesenchymal stem cells use extracellular vesicles to outsource mitophagy and shuttle microRNAs. Nature Communications, 6 , 1-15. https://doi.org/10.1038/ncomms9472.

56. Bruno, S., Grange, C., Deregibus, M. C., Calogero, R. A., Saviozzi, S., Collino, F., Morando, L., Busca, A., Falda, M., Bussolati, B., Tetta, C., \& Camussi, G. (2009). Mesenchymal stem cell-derived microvesicles protect against acute tubular injury. JAm Soc Nephrol., 20(5), 1053-1067. https://doi.org/10.1681/ ASN.2008070798.

57. Collino F, Deregibus MC, Bruno S, et al. (2010) Microvesicles derived from adult human bone marrow and tissue specific mesenchymal stem cells shuttle selected pattern of miRNAs. PLoS One. ;5(7). doi:https://doi.org/10.1371/journal.pone.0011803

58. Reza, A. M. M. T., Choi, Y. J., Yasuda, H., \& Kim, J. H. (2016). Human adipose mesenchymal stem cell-derived exosomalmiRNAs are critical factors for inducing anti-proliferation signalling to A2780 and SKOV-3 ovarian cancer cells. Scientific Reports, 6(May), 1-15. https://doi.org/10.1038/srep38498.

59. Ojo, A. S., Balogun, S. A., Williams, O. T., \& Ojo, O. S. (2020). Pulmonary fibrosis in COVID-19 survivors: Predictive factors and risk reduction strategies. Pulm Med., 2020, 1-10. https://doi.org/ 10.1155/2020/6175964

60. Tay, M. Z., Poh, C. M., Rénia, L., MacAry, P. A., \& Ng, L. F. P. (2020). The trinity of COVID-19: Immunity, inflammation and intervention. Nature Reviews. Immunology, 20(6), 363-374. https://doi.org/10.1038/s41577-020-0311-8.

61. Yang, L., Liu, S., Liu, J., Zhang, Z., Wan, X., Huang, B., Chen, Y., \& Zhang, Y. (2020). COVID-19: Immunopathogenesis and Immunotherapeutics. Signal Transduction and Targeted Therapy, 5(1), 1-8. https://doi.org/10.1038/s41392-020-00243-2.

62. Wiersinga, W. J., Rhodes, A., Cheng, A. C., Peacock, S. J., \& Prescott, H. C. (2020). Pathophysiology, transmission, diagnosis, and treatment of coronavirus disease 2019 (COVID-19): A review. JAMA - J Am Med Assoc., 324(8), 782-793. https://doi. org/10.1001/jama.2020.12839

63. Fajgenbaum, D. C., \& June, C. H. (2020). Cytokine Storm. The New England Journal of Medicine, 383(23), 2255-2273. https:// doi.org/10.1056/NEJMra2026131.

64. Mehta, P., McAuley, D. F., Brown, M., Sanchez, E., Tattersall, R. S., \& Manson, J. J. (2020). COVID-19: Consider cytokine storm syndromes and immunosuppression. Lancet., 395(10229), 10331034. https://doi.org/10.1016/S0140-6736(20)30628-0.

65. Jose, R. J., \& Manuel, A. (2020). COVID-19 cytokine storm: The interplay between inflammation and coagulation. The Lancet Respiratory Medicine, 8(6), e46-e47. https://doi.org/10.1016/ S2213-2600(20)30216-2.

66. Jafarzadeh A, Chauhan P, Saha B, Jafarzadeh S, Nemati M (2020). Contribution of monocytes and macrophages to the local tissue inflammation and cytokine storm in COVID-19: Lessons from SARS and MERS, and potential therapeutic interventions. Life Sci. ;257(January). doi:https://doi.org/10.1016/j.lfs.2020. 118102

67. Coperchini, F., Chiovato, L., Croce, L., Magri, F., \& Rotondi, M. (2020). The cytokine storm in COVID-19: An overview of the involvement of the chemokine/chemokine-receptor system.
Cytokine \& Growth Factor Reviews, 53(May), 25-32. https:// doi.org/10.1016/j.cytogfr.2020.05.003.

68. Amraei, R., \& Rahimi, N. (2020). COVID-19. Renin-Angiotensin System and Endothelial Dysfunction. Cells., 9(7), 1-18. https:// doi.org/10.3390/cells9071652.

69. Bilaloglu, S., Aphinyanaphongs, Y., Jones, S., Iturrate, E., Hochman, J., \& Berger, J. S. (2020). Thrombosis in hospitalized patients with COVID-19 in a new York City health system. JAMA - J Am Med Assoc., 324(8), 799-801. https://doi.org/10.1001/ jama.2020.13372.

70. Kox, M., Waalders, N. J. B., Kooistra, E. J., Gerretsen, J., \& Pickkers, P. (2020). Cytokine levels in critically ill patients with COVID-19 and other conditions. JAMA., 324(15), 1565. https:// doi.org/10.1001/jama.2020.17052.

71. Sinha, P., Matthay, M. A., \& Calfee, C. S. (2020). Is a "cytokine storm" relevant to COVID-19? JAMA Internal Medicine, 180(9), 1152-1154. https://doi.org/10.1001/jamainternmed.2020.3313.

72. Burzynski, L. C., Humphry, M., Pyrillou, K., et al. (2019). The Coagulation and Immune Systems Are Directly Linked through the Activation of Interleukin- $1 \alpha$ by Thrombin. Immunity, 50(4), 1033-1042.e6. https://doi.org/10.1016/j.immuni.2019.03.003.

73. Fan, Y., Guo, T., \& Lu, Z. (2020). Myocardial injury in COVID19-Can we successfully target inflammation?-Reply. JAMA Cardiology, 5(9), 1070-1071. https://doi.org/10.1001/ jamacardio.2020.2572.

74. Levi, M., Thachil, J., Iba, T., \& Levy, J. H. (2020). Coagulation abnormalities and thrombosis in patients with COVID-19. Lancet Haematol., 7(6), e438-e440. https://doi.org/10.1016/S23523026(20)30145-9.

75. Klok, F. A., Kruip, M. J. H. A., van der Meer, N. J. M., Arbous, M. S., Gommers, D. A. M. P. J., Kant, K. M., Kaptein, F. H. J., van Paassen, J., Stals, M. A. M., Huisman, M. V., \& Endeman, H. (2020). Incidence of thrombotic complications in critically ill ICU patients with COVID-19. Thrombosis Research, 191(April), 145147. https://doi.org/10.1016/j.thromres.2020.04.013.

76. Ackermann, M., Verleden, S. E., Kuehnel, M., Haverich, A., Welte, T., Laenger, F., Vanstapel, A., Werlein, C., Stark, H., Tzankov, A., Li, W. W., Li, V. W., Mentzer, S. J., \& Jonigk, D. (2020). Pulmonary vascular Endothelialitis, thrombosis, and angiogenesis in Covid-19. The New England Journal of Medicine, 383, 120-128. https://doi.org/10.1056/nejmoa2015432.

77. Levi, M., \& van der Poll, T. (2017). Coagulation and sepsis. Thrombosis Research, 149, 38-44. https://doi.org/10.1016/j. thromres.2016.11.007.

78. Van Der Poll, T., Levi, M., Hack, C. E., et al. (1994). Elimination of interleukin 6 attenuates coagulation activation in experimental endotoxemia in chimpanzees. The Journal of Experimental Medicine, 179(4), 1253-1259. https://doi.org/10.1084/jem.179.4. 1253.

79. Ridker, P. M., Libby, P., MacFadyen, J. G., et al. (2018). Modulation of the interleukin-6 signalling pathway and incidence rates of atherosclerotic events and all-cause mortality: Analyses from the Canakinumab anti-inflammatory thrombosis outcomes study (CANTOS). European Heart Journal, 39(38), 3499-3507. https://doi.org/10.1093/eurheartj/ehy310.

80. Ridker, P. M., Everett, B. M., Thuren, T., MacFadyen, J. G., Chang, W. H., Ballantyne, C., Fonseca, F., Nicolau, J., Koenig, W., Anker, S. D., Kastelein, J. J. P., Cornel, J. H., Pais, P., Pella, D., Genest, J., Cifkova, R., Lorenzatti, A., Forster, T., Kobalava, Z., Vida-Simiti, L., Flather, M., Shimokawa, H., Ogawa, H., Dellborg, M., Rossi, P. R. F., Troquay, R. P. T., Libby, P., \& Glynn, R. J. (2017). Antiinflammatory therapy with Canakinumab for atherosclerotic disease. The New England Journal of Medicine, 377(12), 1119-1131. https://doi.org/10. 1056/nejmoa1707914. 
81. Zhu, Z., Tang, W., Ray, A., Wu, Y., Einarsson, O., Landry, M. L., Gwaltney Jr., J., \& Elias, J. A. (1996). Rhinovirus stimulation of Interleukin-6 in vivo and in vitro: Evidence for nuclear factor $\mathrm{kB}$ dependent transcriptional activation. The Journal of Clinical Investigation, 97(2), 421-430. https://doi.org/10.1172/ JCI118431.

82. Wang, W., Ye, L., Ye, L., Li, B., Gao, B., Zeng, Y., Kong, L., Fang, X., Zheng, H., Wu, Z., \& She, Y. (2007). Up-regulation of IL- 6 and TNF- $\alpha$ induced by SARS-coronavirus spike protein in murine macrophages via NF-kB pathway. Virus Research, 128(12), 1-8. https://doi.org/10.1016/j.virusres.2007.02.007.

83. Salvarani, C., Dolci, G., Massari, M., Merlo, D. F., Cavuto, S., Savoldi, L., Bruzzi, P., Boni, F., Braglia, L., Turrà, C., Ballerini, P. F., Sciascia, R., Zammarchi, L., Para, O., Scotton, P. G., Inojosa, W. O., Ravagnani, V., Salerno, N. D., Sainaghi, P. P., Brignone, A., Codeluppi, M., Teopompi, E., Milesi, M., Bertomoro, P., Claudio, N., Salio, M., Falcone, M., Cenderello, G., Donghi, L., del Bono, V., Colombelli, P. L., Angheben, A., Passaro, A., Secondo, G., Pascale, R., Piazza, I., Facciolongo, N., Costantini, M., \& RCT-TCZ-COVID-19 Study Group. (2020). Effect of Tocilizumab vs standard care on clinical worsening in patients hospitalized with COVID-19 pneumonia: A randomized clinical trial. JAMA Internal Medicine, 181, 24-31. https://doi.org/10. 1001/jamainternmed.2020.6615.

84. Bari, E., Ferrarotti, I., Saracino, L., Perteghella, S., Torre, M. L., \& Corsico, A. G. (2020). Mesenchymal stromal cell Secretome for severe COVID-19 infections: Premises for the therapeutic use. Cells., 9(4), 5-9. https://doi.org/10.3390/cells9040924.

85. Bayo, J., Real, A., Fiore, E. J., et al. (2017). IL-8, GRO and MCP1 produced by hepatocellular carcinoma microenvironment determine the migratory capacity of human bone marrow-derived mesenchymal stromal cells without affecting tumor aggressiveness. Oncotarget, 8(46), 80235-80248. https://doi.org/10.18632/ oncotarget.10288.

86. Liang-kuan, B., Nan, Z., Cheng, L., Fu-Ding, L., Tian-Xin, L., Xu-Jun, X., Chun, J., Jin-Li, H., Hai, H., Cai-Xia, Z., Wen, D., Hao, L., Jian, H., \& Ke-Wei, X. (2014). Kidney cancer cells secrete IL-8 to activate Akt and promote migration of mesenchymal stem cells. Urol Oncol Semin Orig Investig., 32(5), 607-612. https://doi.org/10.1016/j.urolonc.2013.10.018.

87. Laffey, J. G., \& Matthay, M. A. (2017). Cell-based therapy for acute respiratory distress syndrome: Biology and potential therapeutic value. American Journal of Respiratory and Critical Care Medicine, 196(3), 266-273. https://doi.org/10.1164/rccm. 201701-0107CP.

88. Majolo F, da Silva GL, Vieira L, Timmers LFSM, Laufer S, Goettert MI. Review of trials currently testing stem cells for treatment of respiratory diseases: Facts known to date and possible applications to COVID-19. Stem Cell Reviews and Reports. 2020. doi:https://doi.org/10.1007/s12015-020-10033-6.

89. Emukah, C., Dittmar, E., Naqvi, R., Martinez, J., Corral, A., Moreira, A., \& Moreira, A. (2019). Mesenchymal stromal cell conditioned media for lung disease: A systematic review and meta-analysis of preclinical studies. Respiratory Research, 20(1), 239. https://doi.org/10.1186/s12931-019-1212-x.

90. Tieu, A., Lalu, M. M., Slobodian, M., Gnyra, C., Fergusson, D. A., Montroy, J., Burger, D., Stewart, D. J., \& Allan, D. S. (2020). An analysis of mesenchymal stem cell-derived extracellular vesicles for preclinical use. ACS Nano, 14, 9728-9743. https://doi.org/ 10.1021/acsnano.0c01363.

91. Raab-Traub, N., \& Dittmer, D. P. (2017). Viral effects on the content and function of extracellular vesicles. Nature Reviews. Microbiology, 15(9), 559-572. https://doi.org/10.1038/nrmicro. 2017.60.

92. Pires, A. O., Mendes-Pinheiro, B., Teixeira, F. G., Anjo, S. I., Ribeiro-Samy, S., Gomes, E. D., Serra, S. C., Silva, N. A.,
Manadas, B., Sousa, N., \& Salgado, A. J. (2016). Unveiling the differences of Secretome of human bone marrow mesenchymal stem cells, adipose tissue-derived stem cells, and human umbilical cord perivascular cells: A proteomic analysis. Stem Cells and Development, 25(14), 1073-1083. https://doi.org/10.1089/scd. 2016.0048.

93. Huang, R., Qin, C., Wang, J., et al. (2019). Differential effects of extracellular vesicles from aging and young mesenchymal stem cells in acute lung injury. Aging (Albany NY), 11(18), 7996-8014. https://doi.org/10.18632/aging.102314.

94. Rhoades, M. W., Reinhart, B. J., Lim, L. P., Burge, C. B., Bartel, B., \& Bartel, D. P. (2002). Prediction of plant MicroRNA targets. Cell., 110(4), 513-520. https://doi.org/10.1016/S0092-8674(02) 00863-2.

95. Chauhan N, Jaggi M, Chauhan SC, Yallapu MM. COVID-19: Fighting the invisible enemy with microRNAs. Expert Review of Anti-Infective Therapy 2020;0(0):1-9. doi:https://doi.org/10. 1080/14787210.2020.1812385.

96. Fu, Y., Chen, J., \& Huang, Z. (2019). Recent progress in microRNA-based delivery systems for the treatment of human disease. ExRNA., 1(1), 1-14. https://doi.org/10.1186/s41544019-0024-y.

97. Shah V, Shah J. Recent trends in targeting miRNAs for cancer therapy. Quarterly Journal of Pharmacy and Pharmacology. August 2020:jphp.13351. doi:https://doi.org/10.1111/jphp.13351

98. Fujii, S., Miura, Y., Fujishiro, A., Shindo, T., Shimazu, Y., Hirai, H., Tahara, H., Takaori-Kondo, A., Ichinohe, T., \& Maekawa, T. (2018). Graft-versus-host disease amelioration by human bone marrow mesenchymal stromal/stem cell-derived extracellular vesicles is associated with peripheral preservation of naive $\mathrm{T}$ cell populations. Stem Cells, 36(3), 434 445. https://doi.org/10.1002/ stem. 2759

99. Tanaka, T., Narazaki, M., \& Kishimoto, T. (2016). Immunotherapeutic implications of IL-6 blockade for cytokine storm. Immunotherapy., 8(8), 959-970. https://doi.org/10.2217/ imt-2016-0020.

100. He, L., \& Hannon, G. J. (2004). MicroRNAs: Small RNAs with a big role in gene regulation. Nature Reviews. Genetics, 5(7), 522531. https://doi.org/10.1038/nrg1379.

101. Ti, D., Hao, H., Tong, C., Liu, J., Dong, L., Zheng, J., Zhao, Y., Liu, H., Fu, X., \& Han, W. (2015). LPS-preconditioned mesenchymal stromal cells modify macrophage polarization for resolution of chronic inflammation via exosome-shuttled let-7b. Journal of Translational Medicine, 13(1), 308. https://doi.org/10.1186/ s12967-015-0642-6.

102. Brennan, E., Wang, B., McClelland, A., Mohan, M., Marai, M., Beuscart, O., Derouiche, S., Gray, S., Pickering, R., Tikellis, C., de Gaetano, M., Barry, M., Belton, O., Ali-Shah, S. T., Guiry, P., Jandeleit-Dahm, K. A. M., Cooper, M. E., Godson, C., \& Kantharidis, P. (2017). Protective effect of let-7 miRNA family in regulating inflammation in diabetes-associated atherosclerosis. Diabetes., 66(8), 2266-2277. https://doi.org/10.2337/db16-1405.

103. Buonfiglioli, A., Efe, I. E., Guneykaya, D., et al. (2019). let-7 MicroRNAs Regulate Microglial Function and Suppress Glioma Growth through Toll-Like Receptor 7. Cell Reports, 29(11), 3460-3471.e7. https://doi.org/10.1016/j.celrep.2019.11.029.

104. Sung SY, Liao CH, Wu HP, et al. (2013) Loss of let-7 microRNA upregulates IL-6 in bone marrow-derived mesenchymal stem cells triggering a reactive stromal response to prostate cancer. PLoS One.;8(8). doi:https://doi.org/10.1371/journal.pone.0071637

105. Di T, Yang Y, Fu C, et al. (2020) Let-7 mediated airway remodelling in chronic obstructive pulmonary disease via the regulation of IL-6. European Journal of Clinical Investigation.;(September): 1-13. doi:https://doi.org/10.1111/eci.13425

106. Murugan, N. A., Kumar, S., Jeyakanthan, J., \& Srivastava, V. (2020). Searching for target-specific and multi-targeting organics 
for Covid-19 in the Drugbank database with a double scoring approach. Scientific Reports, 10(1), 1-16. https://doi.org/10. 1038/s41598-020-75762-7.

107. Gaborit, B. J., Bergmann, J. F., Mussini, C., Arribas, J. R., Behrens, G., Walmsley, S., Pozniak, A., \& Raffi, F. (2020). Plea for multitargeted interventions for severe COVID-19. The Lancet Infectious Diseases, 3099(20), 30312-31123. https://doi.org/10. 1016/S1473-3099(20)30312-1.

108. Ferguson, S. W., Wang, J., Lee, C. J., Liu, M., Neelamegham, S., Canty, J. M., \& Nguyen, J. (2018). The microRNA regulatory landscape of MSC-derived exosomes: A systems view. Scientific Reports, 8(1), 1-12. https://doi.org/10.1038/s41598-018-19581-x.

109. Al-Khawaga S, Abdelalim EM (2020). Potential application of mesenchymal stem cells and their exosomes in lung injury: an emerging therapeutic option for COVID-19 patients. European Journal of Clinical Investigation. ;11(1). doi:https://doi.org/10. 1186/s13287-020-01963-6

110. Monsel, A., Zhu, Y. G., Gudapati, V., Lim, H., \& Lee, J. W. (2016). Mesenchymal stem cell derived secretome and extracellular vesicles for acute lung injury and other inflammatory lung diseases. Expert Opinion on Biological Therapy, 16(7), 859871. https://doi.org/10.1517/14712598.2016.1170804.

111. Cheng, L., Zhang, K., Wu, S., Cui, M., \& Xu, T. (2017). Focus on mesenchymal stem cell-derived exosomes: Opportunities and challenges in cell-free therapy. Stem Cells International, 2017, 1-10. https://doi.org/10.1155/2017/6305295.
112. Qiu, G., Zheng, G., Ge, M., Wang, J., Huang, R., Shu, Q., \& Xu, J. (2018). Mesenchymal stem cell-derived extracellular vesicles affect disease outcomes via transfer of microRNAs. Stem Cell Research \& Therapy, 9(1), 1-9. https://doi.org/10.1186/s13287018-1069-9.

113. Mohan, A., Agarwal, S., Clauss, M., Britt, N. S., \& Dhillon, N. K. (2020). Extracellular vesicles: Novel communicators in lung diseases. Respiratory Research, 21(1), 1-21. https://doi.org/10.1186/ s12931-020-01423-y.

114. Khalaj K, Figueira RL, Antounians L, Lauriti G, Zani A. Systematic review of extracellular vesicle-based treatments for lung injury: are EVs a potential therapy for COVID-19? $J$ Extracell Vesicles. 2020;9(1). doi:https://doi.org/10.1080/ 20013078.2020.1795365

115. Qian X, An N, Ren Y, Yang C, Zhang X, Li L. Immunosuppressive effects of mesenchymal stem cells-derived Exosomes. Stem Cell Rev Reports. September 2020. doi:https:// doi.org/10.1007/s12015-020-10040-7.

116. Inal, J. M. (2020). Decoy ACE2-expressing extracellular vesicles that competitively bind SARS-CoV-2 as a possible COVID-19 therapy. Clinical Science, 134(12), 1301-1304. https://doi.org/ 10.1042/CS20200623.

Publisher's Note Springer Nature remains neutral with regard to jurisdictional claims in published maps and institutional affiliations. 